DE-EE0000278

Dynalene Inc.

\title{
Final Scientific/Technical Report
}

\author{
Award Number: DE-EE0000278 \\ Recipient: Dynalene Inc \\ Project Title: Fuel Cell Coolant Optimization and Scale-up \\ Principal Investigator: Satish Mohapatra, $\mathrm{PhD}$ \\ Project Period: October 1, 2009 to August 31, 2011 \\ Working Partners: Lehigh University
}

This report does not contain any proprietary or confidential information. 
DE-EE0000278

Dynalene Inc.

\section{Executive Summary}

Fuel cell technology is moving forward on many fronts via R\&D programs sponsored by the DOE and other agencies. A number of major technical challenges must be addressed before our nation can fully capitalize upon the tremendous potential offered by fuel cells. One of the many elements critical for the success of fuel cell technology is the coolant used in the units. The coolant must meet a series of stringent interrelated performance criteria. One of the many important criteria for the PEM fuel cell coolant is low electrical conductivity (ideally < 10.0 $\mu \mathrm{S} / \mathrm{cm}$ over a period of at least two years). Conventional automotive antifreeze (ethylene glycol or propylene glycol) has very high electrical conductivity (>5000 $\mathrm{S} / \mathrm{cm}$ ) due to the presence of ionic corrosion inhibitors. Electrical conductivity of an uninhibited glycol/water coolant can increase over time because of the production of acidic compounds from glycol as well as the introduction of metal ions into the fluid due to corrosion. There may be leaching of ionic compounds into the fluid from various components present in the coolant loop as well. Fuel cell companies are using de-ionizing canisters (packed with ion-exchange resins) to remove the positive and negative ions present in the coolant fluid. Introduction of a packed bed in the coolant loop causes an additional pressure drop in the system, which reduces system efficiency. Increasing the size of the ion-exchange particles could decrease the pressure drop, but this would reduce the overall surface area of the particles. In that case, the canister would become quickly saturated and would need to be replaced frequently, which increases the operating and maintenance cost. Employing smaller particles can increase the overall surface area (ionexchange capacity), but would increase the pressure drop tremendously.

Dynalene Inc has developed and patented a fuel cell coolant with the help of DOE SBIR Phase I and Phase II funding (Project \# DE-FG02-04ER83884). However, this coolant could only be produced in lab scale (500 $\mathrm{ml}$ to $2 \mathrm{~L}$ ) due to problems in the optimization and scale-up of a nanoparticle ingredient. This project optimized the nanoparticle production process in $10 \mathrm{~L}$ and $100 \mathrm{~L}$ reactors (which translates to about 5000 gallons of coolant), optimized the filtration process for the nanoparticles, and develop a high throughput production as well as quality control method for the final coolant formulation. Scale-up of nanoparticle synthesis (using emulsion polymerization) is an extremely challenging task. Dynalene researchers, in collaboration with a university partner, identified all the parameters affecting the size, charge density and coagulation characteristics of the nanoparticles and then optimized these parameters to achieve the goals and the objectives of this project. Nanaoparticle synthesis was demonstrated to be reproducible in the $10 \mathrm{~L}$ and $100 \mathrm{~L}$ scales.

This project helped Dynalene to launch its fuel cell coolant, Dynalene FC, and it allowed fuel cell developers to reduce the size, weight and cost of their fuel cells. This was particularly important for portable fuel cells. Now that Dynalene is targeting the stationary and automotive fuel cell market with its Dynalene FC and Dynalene LC products, it is expected that the PEM fuel cell community, in general, will be benefited by the savings generated due to the use of these coolants. 
DE-EE0000278

Dynalene Inc.

\subsection{Project Objectives}

The overall objective of the project was to optimize and scale-up the process to make Dynalene FC fuel cell coolant with a great deal of reproducibility. The production of one key ingredient of the coolant, nanoparticles, was to be scaled-up from bench scale to $100 \mathrm{~L}$ pilot-scale. The effect of various process parameters on the size and charge density of the particles were to be determined. The ultimate goal was to develop the capability to produce the nanoparticles necessary for the fuel cell coolant, Dynalene FC, in a very consistent manner. Another technical objective of this project was the optimization of the nanoparticle filtration process to maximize efficiency (maximum removal of unwanted components) when scaling up.

\subsection{Accomplishments}

Dynalene researchers, in collaboration with Lehigh University, successfully performed and completed all the tasks. Nanoparticle synthesis was first scaled up to a $10 \mathrm{~L}$ reactor and then to a $100 \mathrm{~L}$ reactor. After optimizing the process parameters, the particle size and the charge density achieved the targets we were looking for. The two step filtration process was also optimized and the processing time was reduced from several days to less than a day. Multiple batches of the Dynalene FC coolant fluid were produced during the project period and some these were sent to fuel cell developers for testing. The results are so far encouraging. More samples will be sent in the next few months.

\section{Summary of Project Activities}

\subsection{Technical Approach}

As mentioned before, one of the key ingredients in the fuel cell coolant is a nanoparticle. A majority of the effort in this project was devoted to scaling-up the nanoparticle synthesis process from a $2 \mathrm{~L}$ bench-top reactor to a $10 \mathrm{~L}$ reactor, and ultimately to a $100 \mathrm{~L}$ reactor. Experiments on the $500 \mathrm{ml}$ and $2 \mathrm{~L}$ scale of the anionic and cationic nanoparticles (before this project) have led to narrowing down some of the independent and dependent variables. Identifying these variables and then optimizing them in a systematic manner was the main technical approach of our research team.

The reactor type chosen is a jacketed cylindrical vessel with a round bottom. A fully baffled reactor gives slightly higher rates of coagulum, and therefore, not used for scale-up. Instead a single removable baffle was to be used for testing at $10 \mathrm{~L}$ and above.

Following is a list of parameters for optimization:

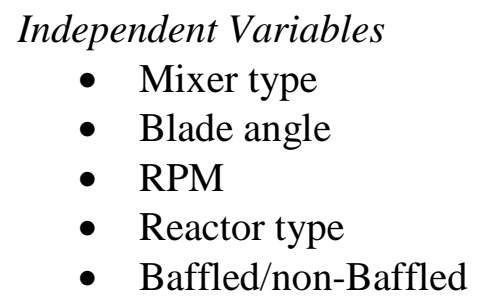


DE-EE0000278

Dynalene Inc.

- Recipe

- Temperature

- Heat transfer mechanism

Dependent Variables

- Size

- Surface charge density

- Yield

- Time of reaction (kinetics)

\subsection{Results and Discussion}

When the Dynalene researchers were producing the cationic and the anionic nanoparticles in 500 $\mathrm{ml}$ and $2 \mathrm{~L}$ bench-top reactors (before the start of this project), they developed two processes. One is a batch polymerization process and the other is a shot growth technique. Both of these recipes produced nanoparticles with the required $200 \mathrm{~nm}$ to $300 \mathrm{~nm}$ particle size, and a 500 to $1000 \mu \mathrm{eq} / \mathrm{g}$ surface charge for cationic and 50 to $100 \mu \mathrm{eq} / \mathrm{g}$ for the anionic particles. This project started with the scale up of cationic particles in $10 \mathrm{~L}$ scale.

\subsubsection{Cationic Nanoparticle Synthesis in $10 \mathrm{~L}$ Scale}

The batch style polymerization recipe was chosen as the starting point for cationic nanoparticle synthesis at the $10 \mathrm{~L}$ scale. In case of batch polymerization, all reaction components are added to the reactor at the start of the synthesis except for the initiator, which is added at the end to start the polymerization. The simplicity of the synthetic method as well as the smaller degree of variables made it a good choice for initial testing.

The first reaction progressed very much like previous experiments at the $2 \mathrm{~L}$ scale with the exception of a considerable exotherm of about $8{ }^{\circ} \mathrm{C}$. No detectable exotherm was ever seen at the $2 \mathrm{~L}$ scale. The reaction visually seemed like a big success. The reaction progressed to $100 \%$ conversion at $17 \%$ solids and a particle size measurement by Dynamic Light Scattering (Nicomp) showed very close to $200 \mathrm{~nm}$. Crude filtration directly from the reactor was quick and efficient. All indications were for a great success especially for the very first run. Particle sizing by Dynamic Light Scattering (DLS) is often unreliable for our synthesis so a sample is always taken to Lehigh University for TEM analysis and confirmation of particle size.

A second identical batch polymerization reaction was run in the $10 \mathrm{~L}$ reactor. This reaction progressed in the same manner as the first and initial indications were that scale-up of this polymerization could be a relatively simple process. However, particle size by TEM showed only about $85 \mathrm{~nm}$, very far from the goal of $200 \mathrm{~nm}$ to $300 \mathrm{~nm}$. As stated earlier, batch polymerization was chosen for initial testing because of its simplicity. Unfortunately, this simplicity also means that a limited number of variables are available for changing the reaction condition toward a more favorable result. For this reason it was decided to switch to the shot growth method going forward. 


\section{DE-EE0000278}

Dynalene Inc.

In a shot growth polymerization, a large portion of the reaction components are added to the reactor at the beginning of the reaction. The reaction is then initiated and is allowed to progress to 80 to $90 \%$ completion before a "shot" of co-monomers is added quickly to the reactor. This gives an added level of control to the reaction because the ratio of co-monomers in the shot has a large effect on the final particles.

The initial shot growth reaction was run at an initial solids concentration of $23 \%$ (by wt.) and a final after shot concentration of $24 \%$. This gives a much more efficient and cost effective synthesis due to the increase in yield over the batch recipe. The shot growth method does require that the rate of conversion in the reaction is known due to the fact that the greatest chance of success is when the shot is added when the initial conversion is 80 to $90 \%$. Unfortunately, the most accurate way to determine reaction conversion is solids percentage by measuring the weight of solid after drying a sample, which takes about two hours to complete. It is possible that when the solids percentage result comes out (after about 2 hours), one has gone beyond the window of opportunity for the shot (or exceeded the 80 to $90 \%$ solids target). For the first run, the shot was done at the same timing as in the $2 \mathrm{~L}$ experiments, 1.5 hours after initiation.

This reaction also progressed well in the initial phase. The shot was added at 1.5 hours without much trouble until about 15 minutes after the addition of the shot. At this point a substantial exotherm of $17^{\circ} \mathrm{C}$ happened in about 10 to 15 minutes. The power was cut from the heating system and the temperature decreased slowly and safely. Due to the large exotherm, the reaction was completed within 15 minutes of the addition of the shot. A TEM of the resultant particles can be seen below in Figure 1. There is an obvious bimodal particle distribution which is not the desired result. It is believed that the large exotherm caused a great deal of secondary nucleation and possibly homo-polymerization of the more water soluble co-monomer which cause the abundance of smaller particles.

The experience with this initial shot growth reaction made it clear that a cooling system was needed for the reactors in order to maintain a constant reaction temperature and a more consistent result. A cooling system with a heat exchanger and temperature control devices was installed as part of the reactor heating system before further testing was resumed.

The next shot growth reaction was done with the shot at 2 hours after initiation. It was later found the reaction was not at a high enough conversion percentage when the shot was added. The data for the reaction is shown in Table 1 below. The addition of a cooling system to the reactor heating system allowed the reaction to progress without any measurable exotherm.

The next shot growth reaction was done with the shot at 3 hours to determine the time of optimum conversion. Again the reaction proceeded with no measurable exotherm. This reaction did produce a large amount of coagulum. It is believed that this could be due to the fact that the initial reaction was already complete when the shot was added. The data for this reaction is in Table 2.

The next challenge was the filtering of the latex after the reaction was complete. Immediately following the reaction, the latex was filtered using a stainless steel filter cartridge with a pore 
DE-EE0000278

Dynalene Inc.

size between 10 and 15 microns. This step removes the larger coagulum that may be produced during the synthesis.

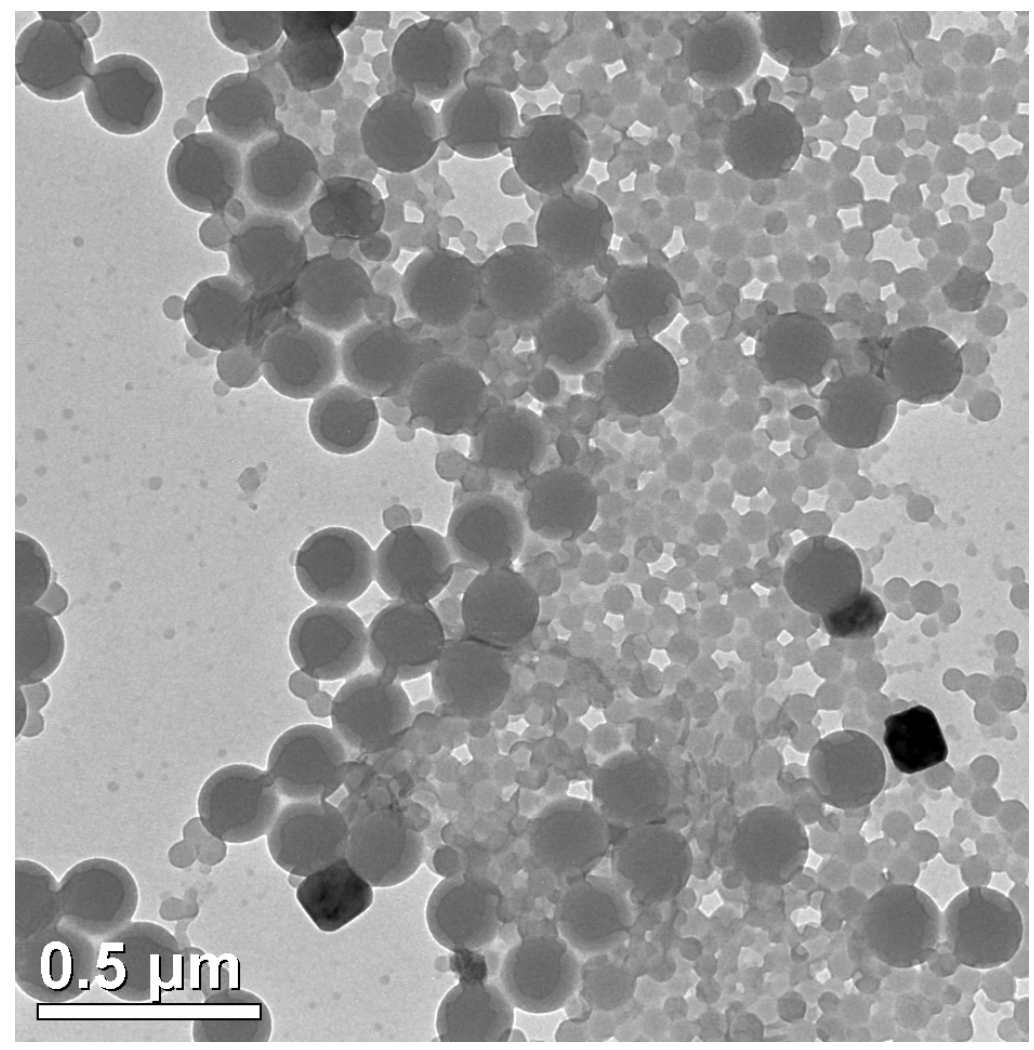

Figure 1: TEM picture of particles produced by shot growth method with shot at $1.5 \mathrm{hr}$ (no cooling provided in the reactor)

Table 1: Shot Growth at 2 hours after initiation

\begin{tabular}{|l|c|l|l|l|l||c|}
\hline Sample & $\begin{array}{c}\text { Time } \\
\text { hours }\end{array}$ & Di/nm & Dv/nm & Dn/nm & PDI & $\begin{array}{l}\text { Percent } \\
\text { Conversion }\end{array}$ \\
\hline $\mathbf{1}$ & 1 & 203.4 & 193.3 & 180.1 & 1.13 & 32 \\
\hline $\mathbf{2}$ & 1.5 & 194.5 & 176.2 & 171.5 & 1.13 & 42 \\
\hline $\mathbf{3}$ & 2 & 201.6 & 191.8 & 186.6 & 1.08 & 66 \\
\hline $\mathbf{4}$ & $\begin{array}{c}0.5 \\
\text { After shot }\end{array}$ & 32.8 & 30.7 & 30.3 & 1.08 & 100 \\
\hline $\mathbf{5}$ & 1 & 272.3 & 267.5 & 259.8 & 1.05 & \\
\hline $\mathbf{6}$ & 1.5 & 291.3 & 274.5 & 266.7 & 1.05 & 100 \\
\hline Final & & 263.6 & 258.0 & 238.6 & 1.10 & 100 \\
\hline
\end{tabular}

Di, Dv and Dn are intensity, volume and number average particle sizes, respectively. 
DE-EE0000278

Dynalene Inc.

Table 2: Shot Growth at 3 hours after initiation

\begin{tabular}{|l|c|l|l|l|l||c|}
\hline Sample & $\begin{array}{c}\text { Time } \\
\text { hours }\end{array}$ & Di/nm & Dv/nm & Dn/nm & PDI & $\begin{array}{l}\text { Percent } \\
\text { Conversion }\end{array}$ \\
\hline $\mathbf{1}$ & 1 & 178.6 & 168.7 & 164.2 & 1.09 & 34 \\
\hline $\mathbf{2}$ & 2 & 193.9 & 176.6 & 172.1 & 1.13 & 60 \\
\hline $\mathbf{3}$ & 2.5 & 219.6 & 200.9 & 195.5 & 1.12 & 90 \\
\hline $\mathbf{4}$ & 3 & 234.5 & 225.9 & 219.7 & 1.07 & 100 \\
\hline $\mathbf{5}$ & 0.5 & 457.4 & 470.8 & 459.0 & 0.99 & \multirow{2}{*}{100} \\
\cline { 3 - 6 } & After shot & 2290.2 & 2301.1 & 2290.2 & 1.00 & \\
\hline $\mathbf{6}$ & 1 & 51.8 & 49.1 & 47.3 & 1.10 & 100 \\
\hline $\mathbf{7}$ & After shot & 465.4 & 479.2 & 467.0 & 0.99 & 100 \\
\hline Final & 1.5 & 423.9 & 442.3 & 425.8 & 0.99 & 100 \\
\hline \hline
\end{tabular}

Di, Dv and Dn are intensity, volume and number average particle sizes, respectively.

Previously (in $500 \mathrm{ml}$ and $2 \mathrm{~L}$ scale), there was little difficulty filtering out the coagulum produced with a lab scale filter setup. However, the larger filters in the pilot plant routinely became clogged and even failed/collapsed completely when the nanoparticles from the $10 \mathrm{~L}$ reactor were filtered. Scanning Electron Micrograph (SEM) images of a collapsed stainless steel cartridge filters are shown in Figure 2 and Figure 3. It can be seen in these figures that 12 to 25 micron larger particles are the cause of the difficult filtering.

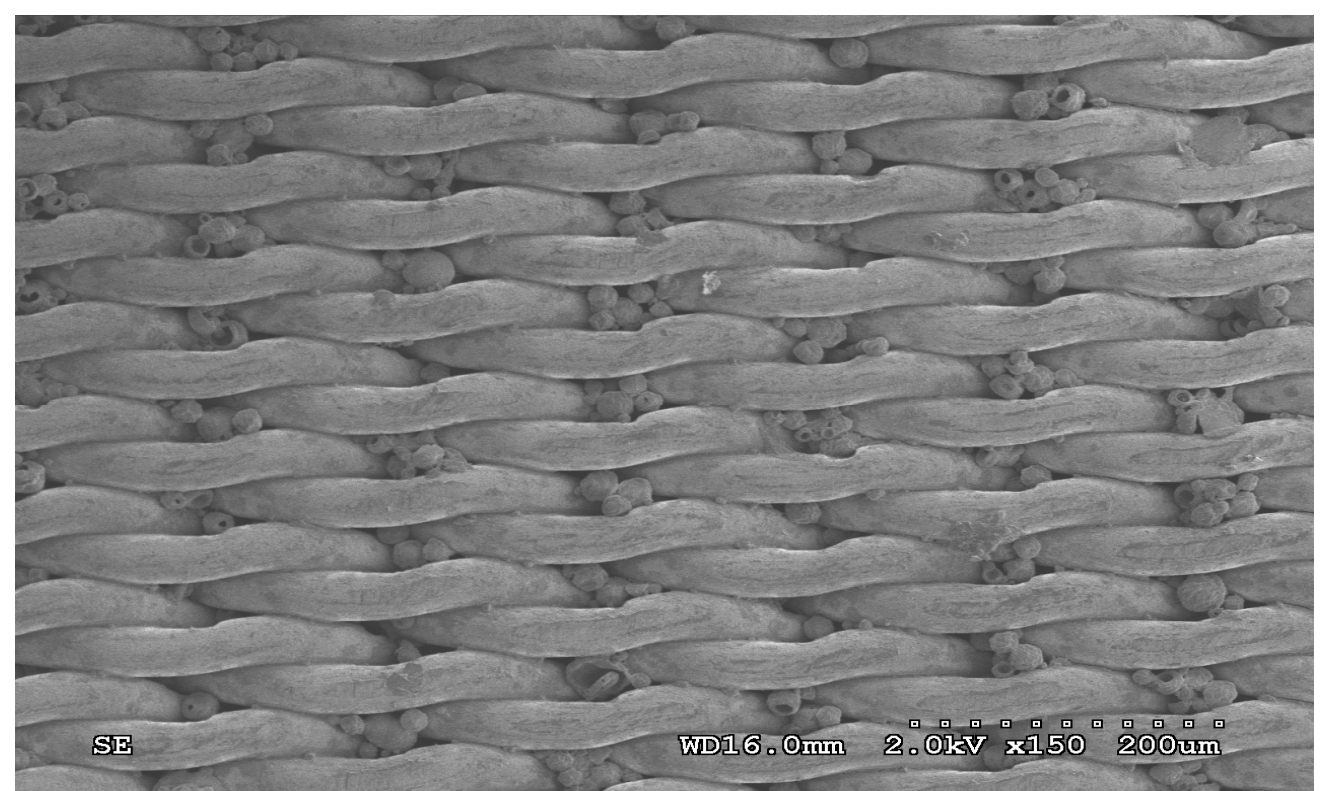

Figure 2: SEM of pilot scale 10 micron stainless steel cartridge filter 
DE-EE0000278

Dynalene Inc.

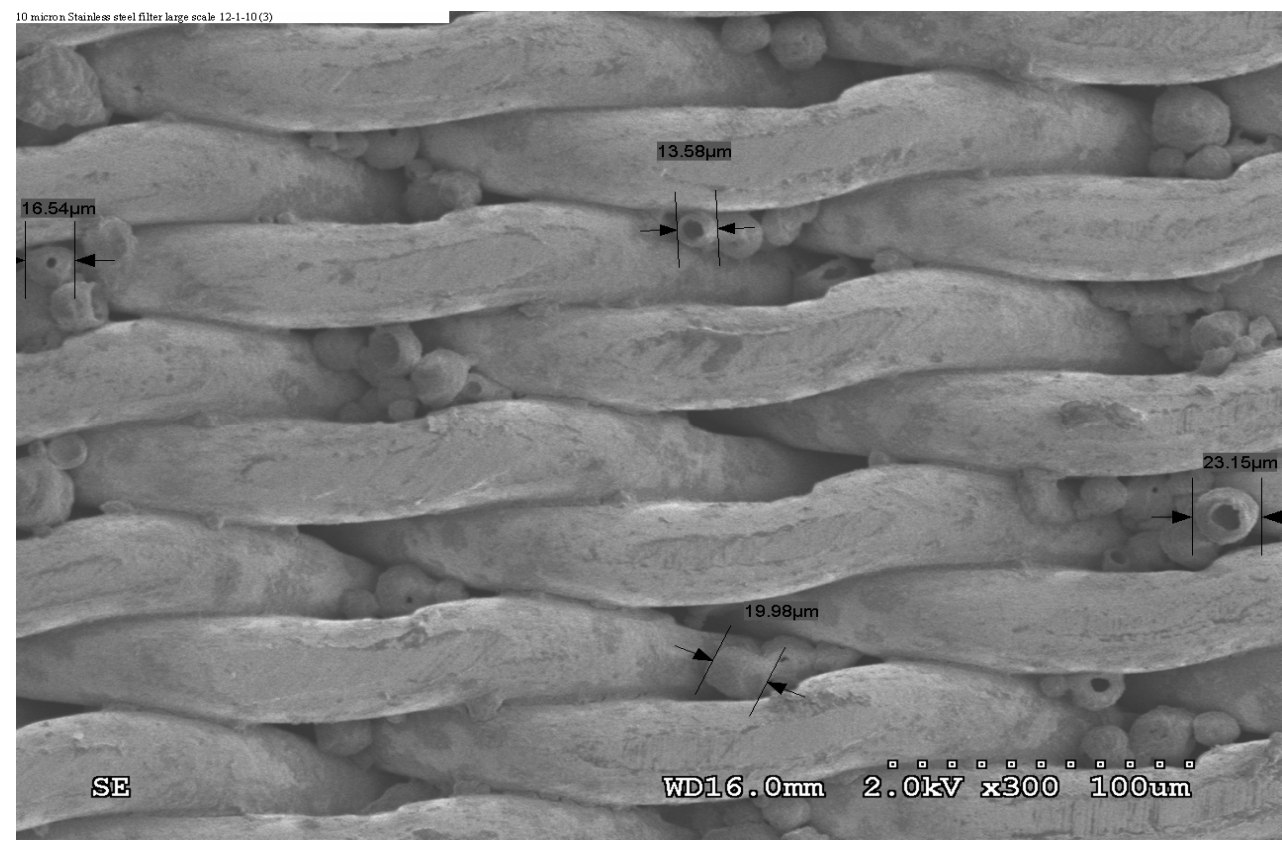

Figure 3: SEM of pilot scale 10 micron stainless steel cartridge filter

To circumvent the problem associated with the filtration (due to the formation of large particles), several approaches were discussed. The first variable to be tested was the use of a dip tube to aid in the proper addition of the shot. This method allows the shot components to be added into the middle of the reaction fluid for immediate uptake into the reaction. Coagulum should be reduced by the elimination of pooling at the air interface. The results of this reaction can be seen in Table 3. Problems with the crude filtering of this reaction were still evident even though it appeared to be coagulum free.

Table 3: 10 L Shot Growth

\begin{tabular}{|c|c|c|c|c|c||c|}
\hline Sample & $\begin{array}{c}\text { Time } \\
\text { hours }\end{array}$ & Di (nm) & Dv (nm) & Dn (nm) & PDI & $\begin{array}{l}\text { Percent } \\
\text { Conversion }\end{array}$ \\
\hline $\mathbf{1}$ & 2 & 178.4 & 168.3 & 159.5 & 1.12 & 57 \\
\hline $\mathbf{2}$ & 2.5 & 199.5 & 159.6 & 178.6 & 1.12 & 85 \\
\hline $\mathbf{3}$ & $\begin{array}{c}0.5 \text { after } \\
\text { shot }\end{array}$ & 279.4 & 275.1 & 267.3 & 1.05 & 100 \\
\hline $\mathbf{4}$ & $\begin{array}{c}\text { 1 after } \\
\text { shot }\end{array}$ & --- & 11.3 & 11.1 & --- & 100 \\
\cline { 3 - 6 } Final & & 278.2 & 273.8 & 265.9 & 1.05 & 100 \\
\hline
\end{tabular}

Di, Dv and Dn are intensity, volume and number average particle sizes, respectively.

The second variable to be tested was the pre-emulsion of the shot components before and during addition. Previously the oil and aqueous components of the shot were added as separate streams making it difficult to control the exact ratio of co-monomers entering the reaction throughout the shot. The volume of the mixed shot is fairly substantial, just under $2 \mathrm{~L}$. A nitrogen bubble line was chosen as the best method for maintaining the emulsion throughout the addition period. The 
DE-EE0000278

Dynalene Inc.

particles produced were of very uniform size within the goal range of the project. The results of the reaction can be seen in Table 4 and an example SEM picture is shown in Figure 4.

Table 4: 10 L Shot Growth

\begin{tabular}{|c|c|c|c|c|c||c|}
\hline Sample & $\begin{array}{c}\text { Time } \\
\text { hours }\end{array}$ & Di/nm & Dv/nm & Dn/nm & PDI & $\begin{array}{l}\text { Percent } \\
\text { Conversion }\end{array}$ \\
\hline $\mathbf{1}$ & 2 & 171.1 & 156.2 & 152.6 & 1.12 & 56 \\
\hline $\mathbf{2}$ & 2.5 & 199.0 & 189.1 & 176.4 & 1.13 & 80 \\
\hline \multirow{2}{*}{3} & $\begin{array}{c}0.5 \text { after } \\
\text { shot }\end{array}$ & 273.8 & 269.0 & 261.3 & 1.05 & \multirow{2}{*}{100} \\
\cline { 2 - 6 } & $\begin{array}{c}5 \text { min } \\
\text { Nicomp }\end{array}$ & 297.6 & 298.3 & 273.3 & 1.09 & \\
\hline \multirow{2}{*}{$\mathbf{F}$} & $\begin{array}{c}1 \text { after } \\
\text { shot }\end{array}$ & 279.6 & 275.4 & 267.6 & 1.04 & 100 \\
\hline Final & & 299.0 & 299.0 & 274.7 & 1.09 & 100 \\
\hline
\end{tabular}

This reaction also presented a problem during crude filtering. The filtering issues made it necessary to determine if the problem was in the new larger filtering system itself or a product of the larger reaction conditions. A series of four identical $2 \mathrm{~L}$ reactions were run for a filtering comparison study. Three of these were combined and filtered using the larger crude filtering skid and one was filtered using the small lab-scale setup. The results of these reactions can be seen in Tables 5, 6, 7, and 8.

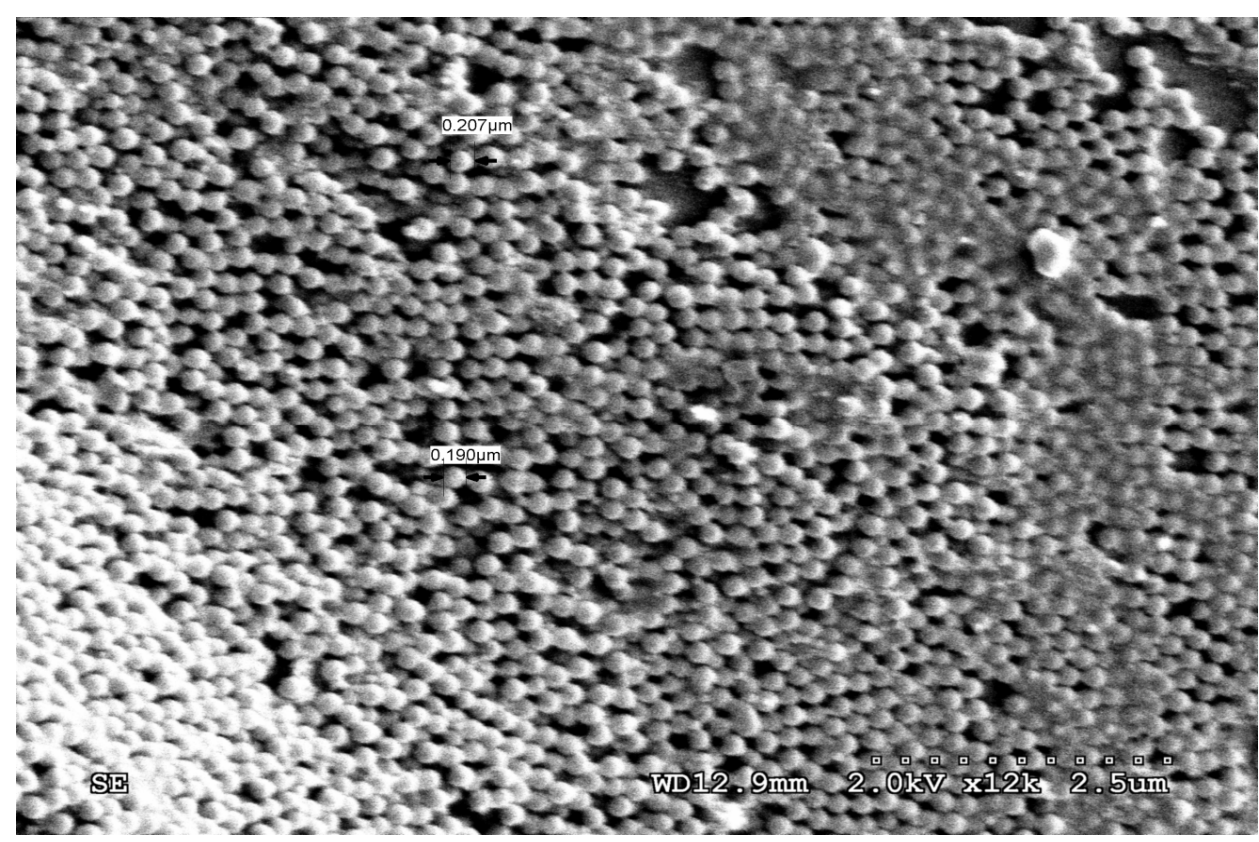

Figure 4: SEM image of 10L shot growth

Table 5: Shot Growth at $2 \mathrm{~L}$ size for filtering comparison \#1 
DE-EE0000278

Dynalene Inc.

\begin{tabular}{|c|c|c|c|c|c||c|}
\hline Sample & $\begin{array}{c}\text { Time } \\
\text { hours }\end{array}$ & Di/nm & Dv/nm & Dn/nm & PDI & $\begin{array}{l}\text { Percent } \\
\text { Conversion }\end{array}$ \\
\hline $\mathbf{1}$ & 0.5 & 118.2 & 109.9 & 102.3 & 1.16 & 20.49 \\
\cline { 3 - 6 } & 280.1 & 278.5 & 273.6 & 1.02 & 29.52 \\
\hline $\mathbf{2}$ & 1.0 & 148.6 & 133.4 & 130.0 & 1.14 & 48.51 \\
\hline $\mathbf{3}$ & 1.5 & 171.3 & 154.6 & 150.6 & 1.14 & 60.72 \\
\hline $\mathbf{4}$ & 2.0 & 171.8 & 162.0 & 153.7 & 1.12 & 91.57 \\
\hline $\mathbf{5}$ & 2.5 & 208.4 & 198.6 & 193.2 & 1.08 & 98.67 \\
\hline $\mathbf{6}$ & 3.0 & 230.9 & 222.0 & 207.4 & 1.11 & 98.11 \\
\hline $\mathbf{7}$ & 3.5 & 227.2 & 218.4 & 205.4 & 1.11 & 97.04 \\
\hline $\mathbf{8}$ & $\begin{array}{c}0.5 \text { after } \\
\text { shot }\end{array}$ & 353.8 & 383.0 & 353.0 & 1.00 & 98.43 \\
\hline $\mathbf{9}$ & $\begin{array}{c}1.0 \text { after } \\
\text { shot }\end{array}$ & 366.1 & 394.6 & 384.2 & 1.05 & \\
\hline Final & & 367.5 & 385.4 & 377.6 & 1.03 & \\
\hline
\end{tabular}

Table 6: Shot Growth at $2 \mathrm{~L}$ size for filtering comparison \#2

\begin{tabular}{|c|c|c|c|c|c|c|}
\hline Sample & $\begin{array}{c}\text { Time } \\
\text { hours }\end{array}$ & $\mathrm{Di} / \mathbf{n m}$ & Dv/nm & Dn/nm & PDI & \begin{tabular}{|l} 
Percent \\
Conversion
\end{tabular} \\
\hline \multirow{2}{*}{1} & \multirow{2}{*}{2.0} & 78.6 & 73.6 & 71.2 & 1.10 & \multirow{2}{*}{27.08} \\
\hline & & 195.1 & 172.4 & 167.7 & 1.16 & \\
\hline 2 & 2.5 & 191.5 & 173.8 & 169.2 & 1.13 & 43.63 \\
\hline 3 & 3.0 & 203.4 & 193.6 & 188.4 & 1.08 & 50.52 \\
\hline 4 & 3.5 & 221.8 & 203.1 & 197.7 & 1.12 & 68.59 \\
\hline \multirow{2}{*}{5} & \multirow{2}{*}{$\begin{array}{c}0.5 \text { after } \\
\text { shot }\end{array}$} & 213.1 & 207.4 & 203.9 & 1.05 & \multirow{2}{*}{98.73} \\
\hline & & 510.4 & 525.5 & 510.4 & 1.00 & \\
\hline Final & & & & & & \\
\hline
\end{tabular}

Table 7: Shot Growth at 2 L size for filtering comparison \#3

\begin{tabular}{|c|c|c|c|c|c|c|}
\hline Sample & $\begin{array}{c}\text { Time } \\
\text { hours }\end{array}$ & Di/nm & Dv/nm & Dn/nm & PDI & $\begin{array}{l}\text { Percent } \\
\text { Conversion }\end{array}$ \\
\hline $\mathbf{1}$ & 0.5 & 115.8 & 107.8 & 102.9 & 1.13 & 27.06 \\
\hline $\mathbf{2}$ & 1.0 & 137.0 & 128.1 & 124.7 & 1.10 & 42.06 \\
\hline $\mathbf{3}$ & 1.5 & 169.1 & 153.5 & 149.7 & 1.13 & 58.27 \\
\hline $\mathbf{4}$ & 2.0 & 33.6 & 33.1 & 32.9 & 1.02 & 87.64 \\
\cline { 2 - 6 } & 192.4 & 175.3 & 170.8 & 1.13 & 98.51 \\
\hline $\mathbf{5}$ & 2.5 & 201.1 & 191.3 & 186.2 & 1.08 & 98.10 \\
\hline $\mathbf{6}$ & 3.0 & 205.3 & 195.3 & 190.0 & 1.08 & 98.48 \\
\hline $\mathbf{7}$ & 3.5 & 203.6 & 193.6 & 188.3 & 1.08 & 98.03 \\
\hline $\mathbf{8}$ & 0.5 after & 368.2 & 395.2 & 385.3 & 1.05 & \\
\hline
\end{tabular}


DE-EE0000278

Dynalene Inc.

\begin{tabular}{|c||c|c|c|c|c|c|}
\hline \multirow{3}{*}{9} & \multirow{2}{*}{$\begin{array}{c}1.0 \text { after } \\
\text { shot }\end{array}$} & 67.7 & 66.8 & 69.9 & 1.03 & \multirow{2}{*}{99.51} \\
\cline { 3 - 6 } & & 124.5 & 123.2 & --- & --- & \\
\cline { 3 - 6 } & & 453.0 & 467.0 & 454.8 & 1.00 & \\
\hline
\end{tabular}

Table 8: Shot Growth at $2 \mathrm{~L}$ size for filtering comparison \#4

\begin{tabular}{|c|c|c|c|c|c||c|}
\hline Sample & $\begin{array}{c}\text { Time } \\
\text { hours }\end{array}$ & Di/nm & Dv/nm & Dn/nm & PDI & $\begin{array}{l}\text { Percent } \\
\text { Conversion }\end{array}$ \\
\hline $\mathbf{1}$ & 2.0 & 146.9 & 128.3 & 117.7 & 1.25 & 98.58 \\
\hline $\mathbf{2}$ & 2.5 & 134.4 & 125.6 & 119.5 & 1.12 & 99.02 \\
\hline $\mathbf{3}$ & 3.0 & 133.0 & 124.3 & 118.6 & 1.12 & 98.97 \\
\hline $\mathbf{4}$ & 3.5 & 135.5 & 126.6 & 120.2 & 1.13 & 99.33 \\
\hline $\mathbf{5}$ & $\begin{array}{c}0.5 \text { after } \\
\text { shot }\end{array}$ & 319.8 & 339.1 & 314.1 & 1.02 & 101.31 \\
\hline
\end{tabular}

All of the $2 \mathrm{~L}$ reactions for the filtering study produced a fairly large amount of coagulum as shown in Figures 5 and 6 below:

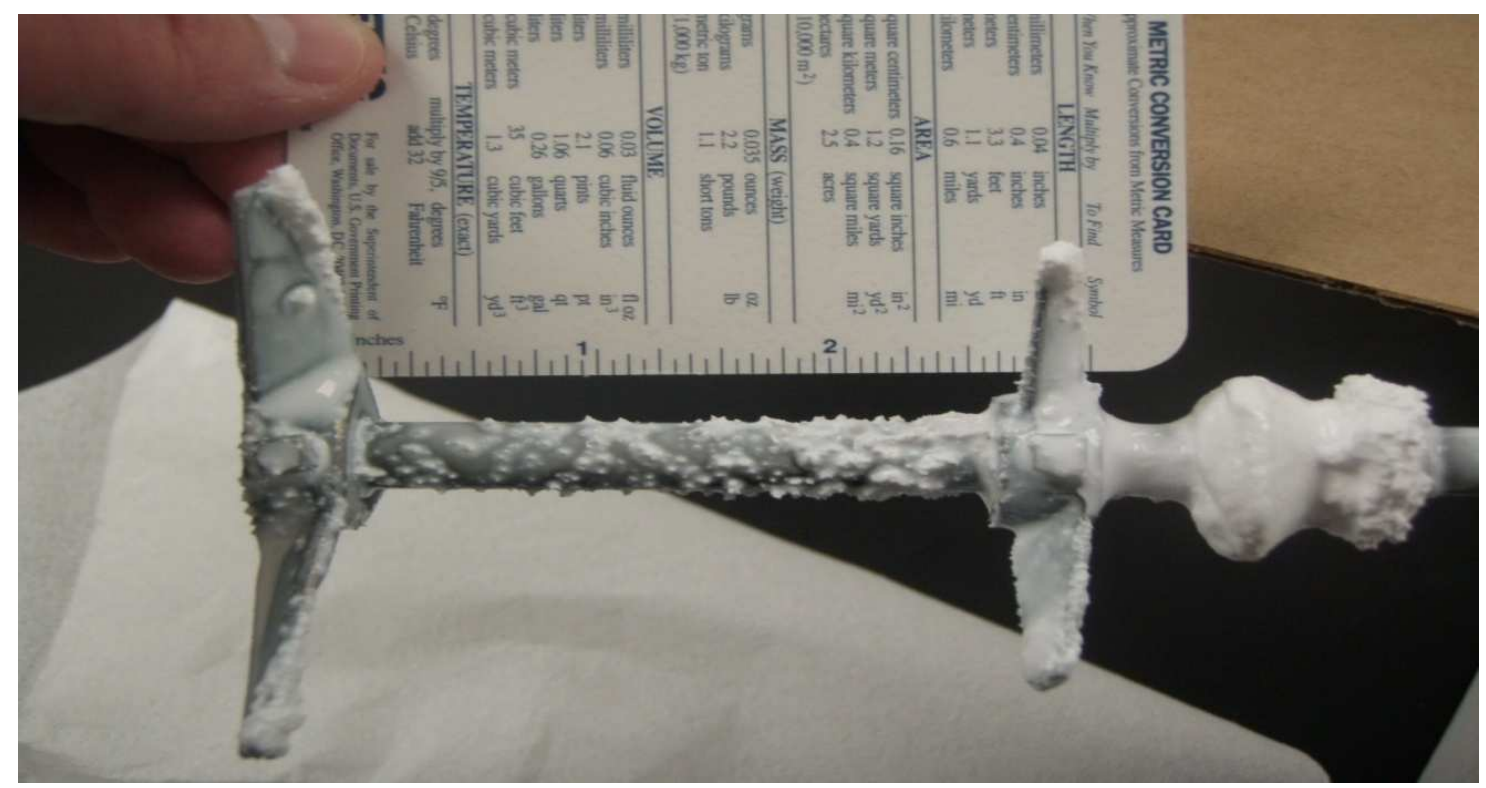

Figure 5: $2 \mathrm{~L}$ reactor coagulum 
DE-EE0000278

Dynalene Inc.

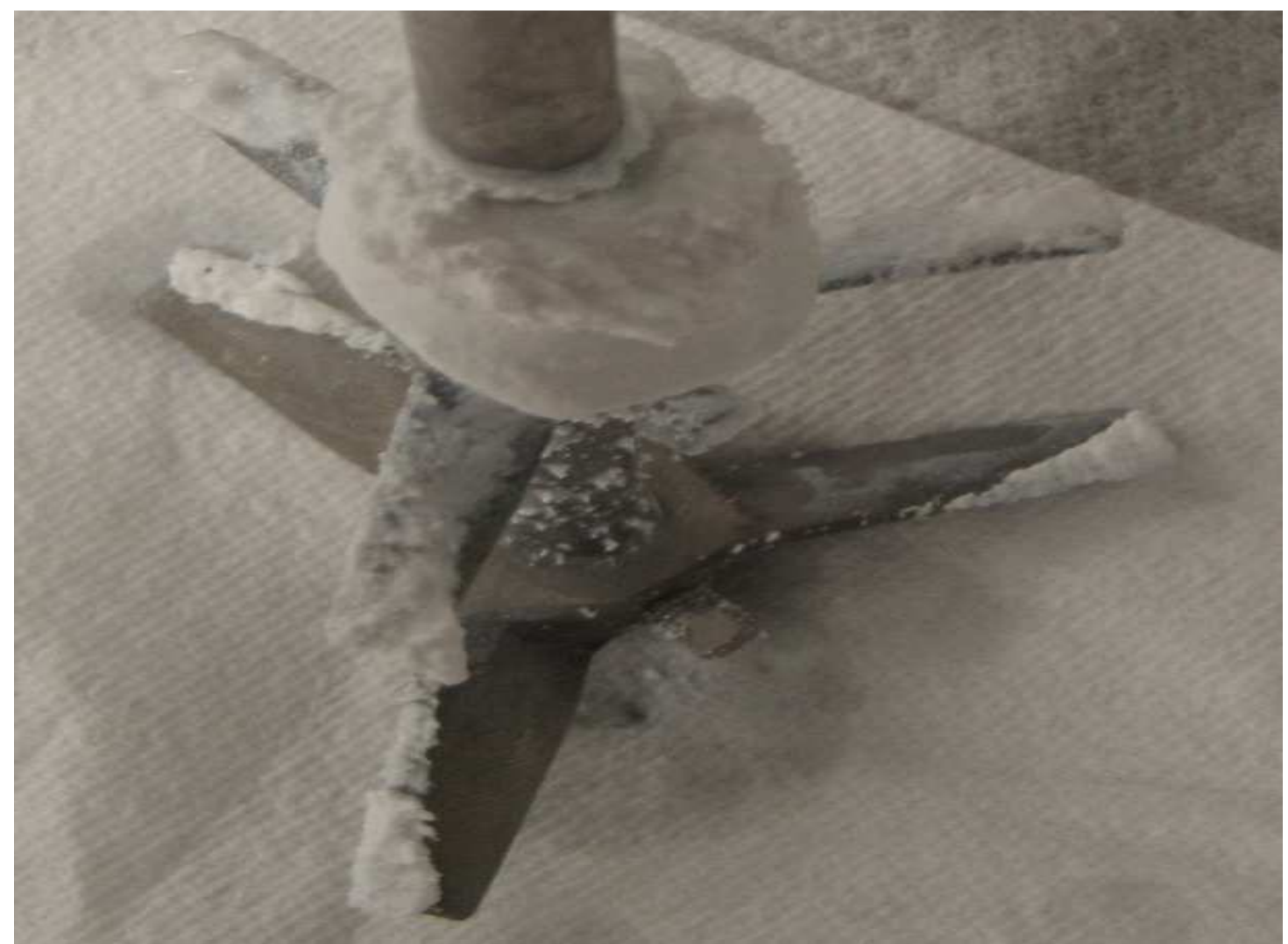

Figure 6: 2 L reaction coagulum

The $2 \mathrm{~L}$ reactions even with the relatively large amount of coagulum were able to be filtered through the lab scale filtering system. Problems still arose while filtering through the pilot scale system. This prompted a search for a new type of filter at the pilot scale, as well as a set of $10 \mathrm{~L}$ experiments aimed at reducing the overall amount of coagulum produced. The simplest method for reducing coagulum was to reduce the stirring speed while keeping all other parameters constant.

The slower mixing speed was not sufficient to bring the reaction to completion. Before the shot, there was still a small styrene layer present on top of the latex. The shot was added in a preemulsified form but appeared to separate after addition. The styrene rose to the top and the size of the layer increased. The reaction was allowed to proceed overnight. The styrene layer turned into a non-uniform gel.

Mixing studies with oil and dye were done prior to the next reaction in order to determine proper impeller placement and stirring speed. Even with that work, the reaction did not go well. There was a very large amount of coagulum. A picture of the coagulum can be seen in Figure 7. The coagulum at the bottom of the reactor was about 2.5 to 3 inches thick, quite substantial and not at all the result we were hoping for.

This result prompted the addition of a third impeller to the reactor in order to increase mixing at the slower stirring speeds. A dyed oil and water study was done with this configuration as well. Proper mixing was observed at an optimum RPM/impeller combination. 
DE-EE0000278

Dynalene Inc.

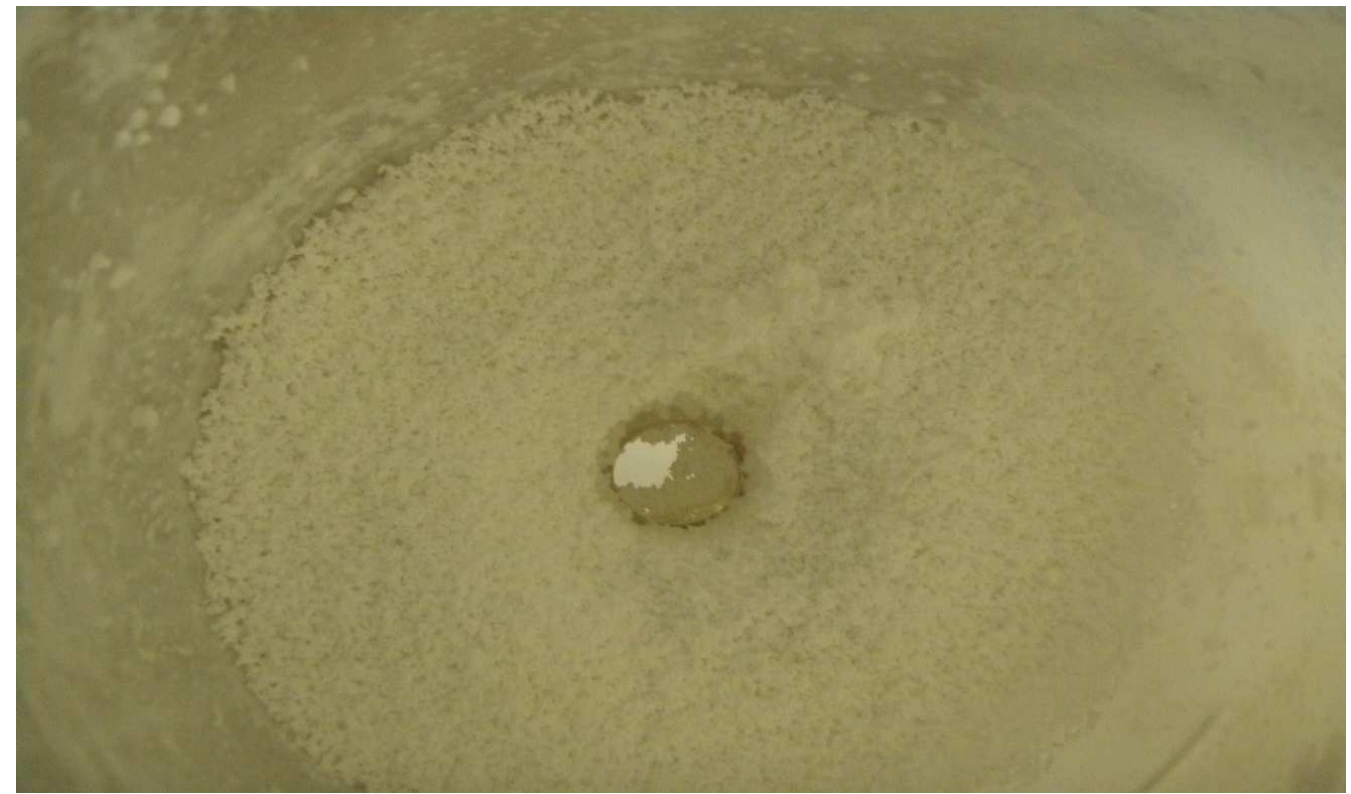

\section{Figure 7: $10 \mathrm{~L}$ reactor coagulum}

Several reactions have been run with the multi impeller set up in combination with the slower stirring speed. The results are excellent so far. These results can be seen in Tables 9, 10 and 11 .

Table 9: $10 \mathrm{~L}$ shot growth with slower stirring

\begin{tabular}{|c|c|c|c|c|c||c|}
\hline Sample & \multirow{2}{*}{$\begin{array}{c}\text { Time } \\
\text { hours }\end{array}$} & Di/nm & Dv/nm & Dn/nm & PDI & $\begin{array}{l}\text { Percent } \\
\text { Conversion }\end{array}$ \\
\hline $\mathbf{1}$ & 2.0 & 182.7 & 172.7 & 167.9 & 1.09 & 48.3 \\
\hline $\mathbf{2}$ & 2.5 & 197.6 & 187.9 & 178.2 & 1.11 & 68.5 \\
\hline $\mathbf{3}$ & $\begin{array}{c}0.5 \mathrm{hrs} \\
\text { after shot }\end{array}$ & 181.0 & 169.9 & 164.8 & 1.10 & \multirow{2}{*}{101.9} \\
\hline
\end{tabular}

Table 10: $10 \mathrm{~L}$ shot growth with slower stirring

\begin{tabular}{|c|c|c|c|c|c||c|}
\hline Sample & $\begin{array}{c}\text { Time } \\
\text { hours }\end{array}$ & Di/nm & Dv/nm & Dn/nm & PDI & $\begin{array}{l}\text { Percent } \\
\text { Conversion }\end{array}$ \\
\hline $\mathbf{1}$ & 1.0 & 150.7 & 135.7 & 132.4 & 1.14 & 36.7 \\
\hline $\mathbf{2}$ & 2.0 & 179.1 & 169.2 & 164.7 & 1.09 & 59.8 \\
\hline $\mathbf{3}$ & 2.5 & 206.8 & 196.8 & 191.3 & 1.08 & 85.6 \\
\hline $\mathbf{4}$ & 3.0 & 224.8 & 207.0 & 201.8 & 1.11 & 97.4 \\
\hline $\mathbf{5}$ & $\begin{array}{c}0.5 \mathrm{hrs} \\
\text { after shot }\end{array}$ & 396.5 & 409.4 & 398.7 & 1.00 & 100.0 \\
\hline $\mathbf{6}$ & $\begin{array}{c}1.0 \mathrm{hrs} \\
\text { after shot }\end{array}$ & 400.9 & 457.8 & 403.4 & 1.01 & 100.0 \\
\hline
\end{tabular}


DE-EE0000278

Dynalene Inc.

Table 11: $10 \mathrm{~L}$ shot growth with slower stirring

\begin{tabular}{|c|c|c|c|c|c|c|}
\hline Sample & $\begin{array}{l}\text { Time } \\
\text { hours }\end{array}$ & Di/nm & $\mathrm{Dv} / \mathrm{nm}$ & Dn/nm & PDI & $\begin{array}{l}\text { Percent } \\
\text { Conversion }\end{array}$ \\
\hline 1 & 1.0 & 156.1 & 146.4 & 138.8 & 1.12 & 35.8 \\
\hline 2 & 1.5 & 194.6 & 177.5 & 173.0 & 1.12 & 48.5 \\
\hline 3 & 2.0 & 190.7 & 172.9 & 168.3 & 1.13 & 61.2 \\
\hline 4 & 2.5 & 220.3 & 201.8 & 196.3 & 1.12 & 86.4 \\
\hline 5 & 3.0 & 223.5 & 204.5 & 199.0 & 1.12 & 95.8 \\
\hline 6 & \begin{tabular}{|c|}
$0.5 \mathrm{hrs}$ \\
after shot
\end{tabular} & 412.6 & 425.4 & 414.7 & 1.02 & 98.2 \\
\hline \multirow{2}{*}{6} & \multirow{2}{*}{$\begin{array}{c}1.0 \mathrm{hrs} \\
\text { after shot }\end{array}$} & 186.0 & 175.9 & 170.9 & 1.09 & \multirow{2}{*}{98.2} \\
\hline & & 536.9 & 553.1 & 536.9 & 1.00 & \\
\hline
\end{tabular}

SEM picture showed a very uniform, consistent particle size in the $200 \mathrm{~nm}$ range (Figures 8 and 9). Surface charge density is also within the expected range. To demonstrate the repeatability of this method, four identical batches were produced and the particle size and the charge density were measured. The results shown in Table 12 indicated a great deal of repeatability of this method.

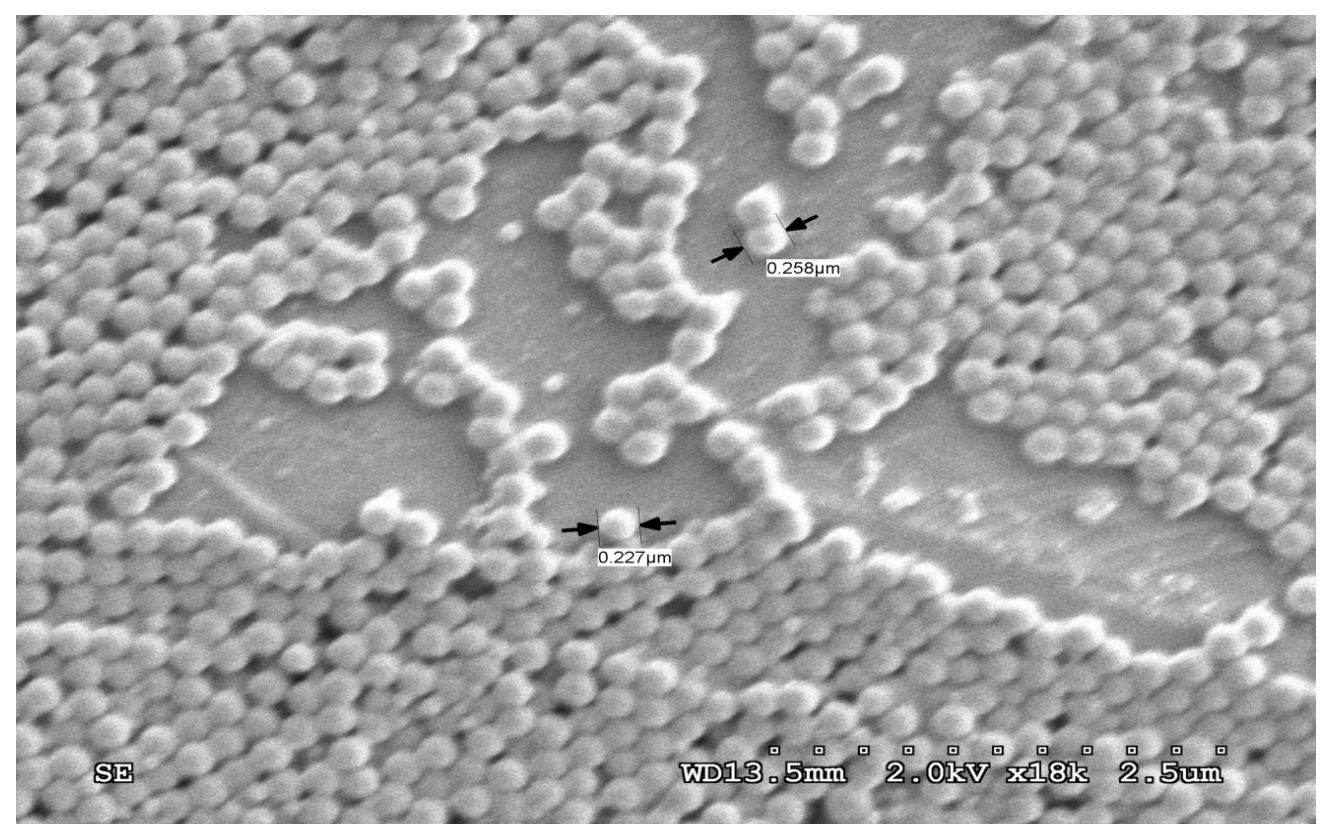

Figure 7: SEM image of cationic nanoparticles 
DE-EE0000278

Dynalene Inc.

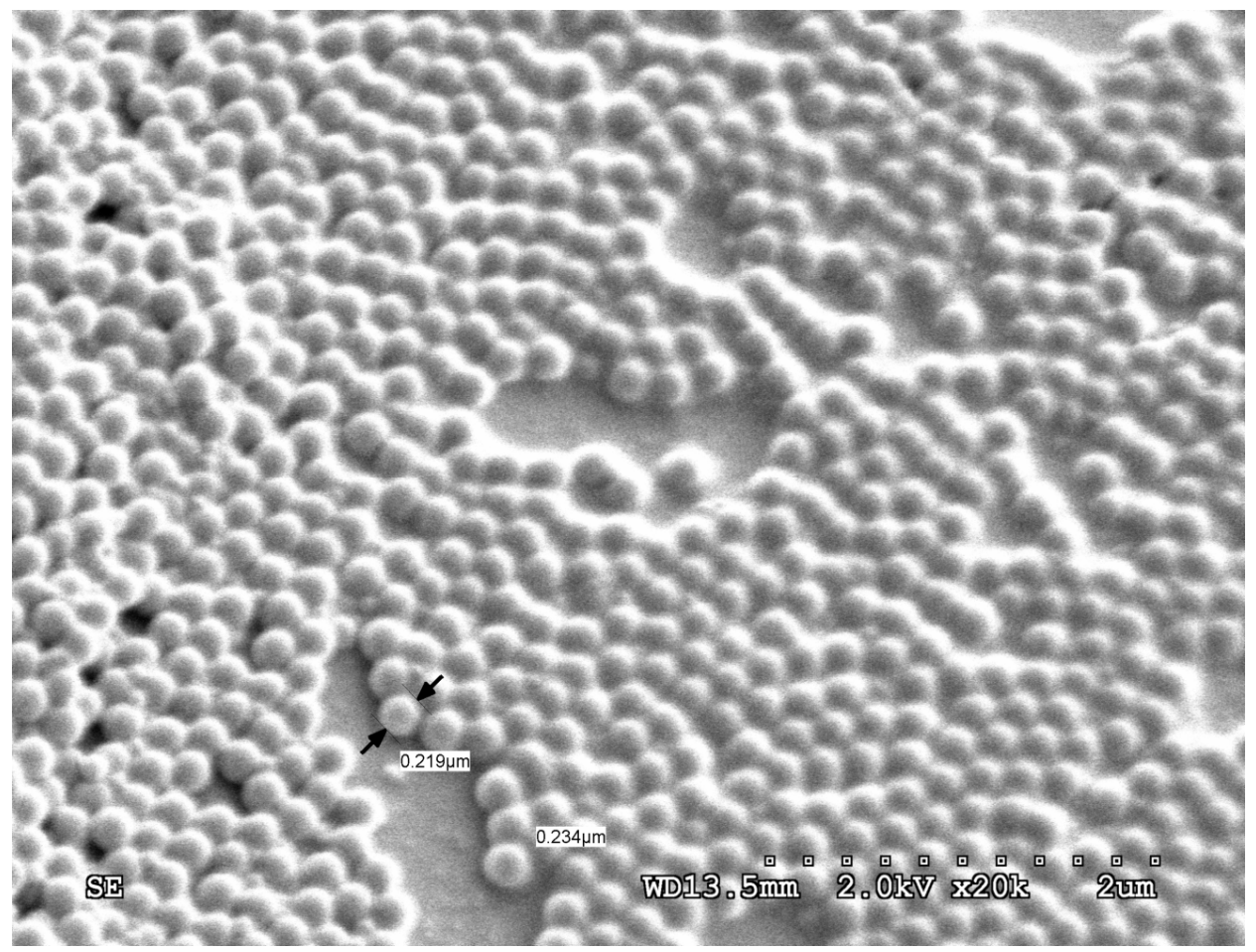

Figure 8: SEM image of cationic nanoparticles

Table 12: $10 \mathrm{~L}$ scale cationic particle experiments with optimized parameters

\begin{tabular}{|c|c|c|c|}
\hline Experiment & Reaction type & $\begin{array}{c}\text { Particle Size } \\
(\mathbf{n m})\end{array}$ & $\begin{array}{c}\text { Surface Charge Density } \\
(\boldsymbol{\mu e q} / \mathbf{g})\end{array}$ \\
\hline JWM-0002-07 & 10L shot growth & 230 & $500-1000$ \\
\hline JWM-0002-10 & 10L shot growth & 225 & $500-1000$ \\
\hline JWM-0002-12 & 10L shot growth & 230 & $500-1000$ \\
\hline JWM-0002-14 & 10L shot growth & 235 & $500-1000$ \\
\hline
\end{tabular}

\subsubsection{Anionic Nanoparticle Synthesis in 10 L Scale}

Work on the anionic nanoparticle synthesis was initially performed by researchers from Lehigh University. Due to the low surface charge density observed in our prior research experiments with anionic particles, initial experiments were conducted at the $500 \mathrm{ml}$ and $2 \mathrm{~L}$ scale to enhance the recipe and increase the anionic charge at the surface of the particles.

The goal of this project is to prepare nanoparticless with particle diameters ranging from $200 \mathrm{~nm}$ to $250 \mathrm{~nm}$ with high surface charge densities. We were successful in preparing particles with a size of $210 \mathrm{~nm}$ and surface charge density of $110 \mu \mathrm{eq} / \mathrm{g}$ on a $500 \mathrm{ml}$ scale, via a semi-batch emulsion polymerization process. The next objective of this program was to scale up the synthesis to a $2 \mathrm{~L}$ scale. 


\section{DE-EE0000278}

Dynalene Inc.

In previous work carried out on the $500 \mathrm{ml} \mathrm{scale}$, the latex particle size could be well controlled between $200 \mathrm{~nm}$ and $250 \mathrm{~nm}$ and the semi-batch process was used to improve the surface charge density from 40 to $110 \mu \mathrm{eq} / \mathrm{g}$. The results obtained from the different scaling of batch polymerization are shown in Table 13. When the reactor size was increased from $500 \mathrm{ml}$ to $2 \mathrm{~L}$, the particle size and surface charge density both changed: the particle size is smaller and the surface charge density is higher when employing the $2 \mathrm{~L}$ reactor. When the reactor scale is larger, there is more reaction heat accumulated inside the reactor and the heat exchange efficiency is lower. So the use of the larger reactor will result in a higher reaction temperature during the polymerization. In previous studies, a higher reaction temperature resulted in the formation of smaller latex particles. When the particle size is smaller, the surface area per gram of polymer is increased and the surface charge density also increases. In addition, when the reactor scale is larger, the amount of coagulum also increases, which may be caused by mixing inefficiency. When the reactor is larger, the mixing efficiency is lower. The low mixing efficiency may result in a problem of an inhomogeneous distribution of monomer dispersion. The monomer, which is not dispersed well, may swell the polymer particles or form a polymer skin layer and results in increased coagulum formation. The fractional conversions between the $500 \mathrm{ml}$ and $2 \mathrm{~L}$ reactors are compared, as shown in Figure 9. The $2 \mathrm{~L}$ scale exhibited a higher polymerization rate and reaches high conversion earlier, which is caused by the reaction temperature influence.

Table 13: Results obtained from the batch copolymerization of styrene with anionic comonomer at different reactor sizes

\begin{tabular}{|l|l|l|l|l|l|l|l|l||}
\hline $\begin{array}{l}\text { Reactor } \\
\text { Size }\end{array}$ & Solids & Conversion & Coagulum & $\mathrm{D}_{\mathrm{i}} / \mathrm{nm}$ & $\mathrm{D}_{\mathrm{v}} / \mathrm{nm}$ & $\mathrm{D}_{\mathrm{n}} / \mathrm{nm}$ & PDI & $\begin{array}{l}\text { SCD } \\
/ \mu \mathrm{eq} / \mathrm{g}\end{array}$ \\
\hline \hline $500 \mathrm{ml}$ & $25.7 \%$ & $97.35 \%$ & $0.25 \%$ & 243.6 & 242.8 & 238.8 & 1.02 & 47.5 \\
\hline $2 \mathrm{~L}$ & $25.17 \%$ & $99.00 \%$ & $2.12 \%$ & 206.1 & 204.0 & 199.3 & 1.03 & 63.9 \\
\hline
\end{tabular}

Di, Dv and Dn are intensity, volume and number average particle diameter, respectively.

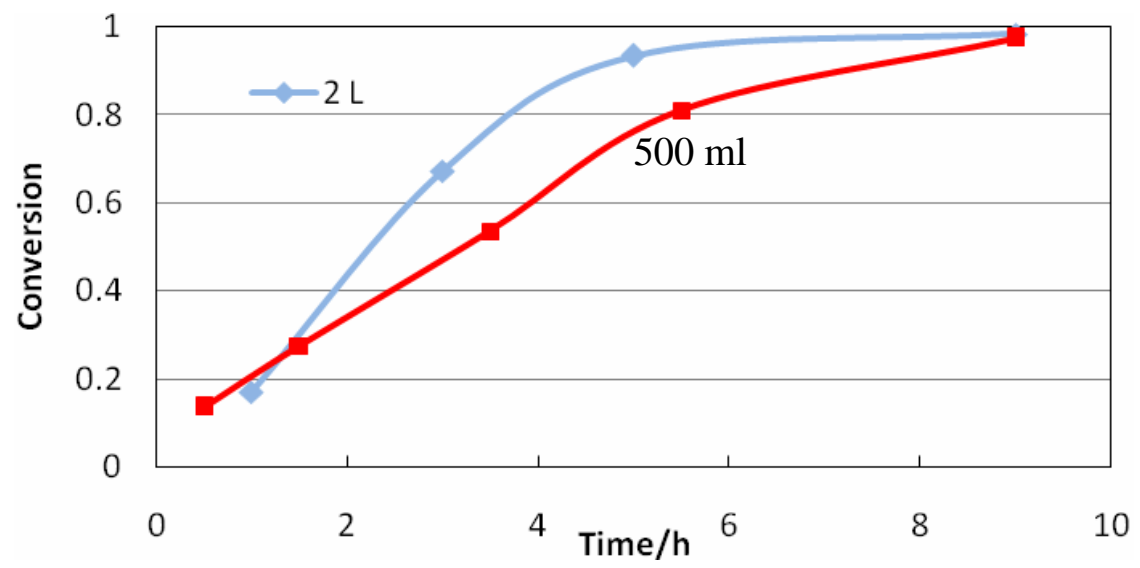

Figure 9: Fractional conversions for batch polymerizations with $500 \mathrm{ml}$ and $2 \mathrm{~L}$ reactors.

The influences of different mixing conditions on batch polymerization on the $2 \mathrm{~L}$ scale were also studied. The results are shown in Table 14. When one impeller was used at $200 \mathrm{rpm}$, there was a big vortex of monomer formed in the center of the reactor on top of the surface. The monomer 


\section{DE-EE0000278}

Dynalene Inc.

vortex could be dispersed by using a two impeller configuration at $250 \mathrm{rpm}$; however, the amount of coagulum also increased, which was caused by the high shear force. A longer reaction time also increased the amount of coagulum. The surface charge density was around $60 \mu \mathrm{eq} / \mathrm{g}$, which needed to be improved by using a semi-batch emulsion polymerization process.

Table 14: Results of the Batch Process at Different Mixing Conditions

\begin{tabular}{|l|l|l|l|l|l|l|l|l||}
\hline Exp. & Solids & Conversion & Coagulum & $\mathrm{D}_{\mathrm{i}} / \mathrm{nm}$ & $\mathrm{D}_{\mathrm{v}} / \mathrm{nm}$ & $\mathrm{D}_{\mathrm{n}} / \mathrm{nm}$ & PDI & $\begin{array}{l}\text { SCD } \\
/ \mu \mathrm{eq} / \mathrm{g}\end{array}$ \\
\hline \hline 072910 & $25.12 \%$ & $99.98 \%$ & $4.43 \%$ & 207.9 & 194.6 & 160.3 & 1.29 & 57.2 \\
\hline 080510 & $25.17 \%$ & $99.00 \%$ & $2.12 \%$ & 206.1 & 204.0 & 199.3 & 1.03 & 63.9 \\
\hline
\end{tabular}

The influence of the different recipes in the semi-batch emulsion polymerization in the $2 \mathrm{~L}$ reactor was also studied. The results are shown in Table 15. The anionic comonomer solution and styrene were fed separately into the reaction. From the results of these semi-batch processes, the consistency of the experiments was not good. There was a lot of fluctuation in the conversion of the seed stage as well as in the surface charge density values. The conversion of the seed is critical for the surface charge density of the final latex. The ideal time to start the second stage feed should be from $85 \%$ to $95 \%$ conversion. There are two possible causes for the fluctuation in these values. One is the mixing. For the $2 \mathrm{~L}$ scale, mixing is not as good as in the $500 \mathrm{ml} \mathrm{scale}$. The seed conversion may be influenced by the stability of the emulsion. The other factor is the decomposition rate of the initiator. The initiator decomposes much faster and generates radicals quickly under the low $\mathrm{pH}$ conditions. When comonomer A was used, the $\mathrm{pH}$ was only around 1.5. In this case, the initiator may not generate enough radicals due to the quick initiator decomposition. Therefore, a baffled reactor was used to improve the efficiency of mixing and feeding of the initiator solution was used to even out the radicals' generation rate.

Table 15: Results of the batch copolymerization

\begin{tabular}{|l|l|l|l|l|l|l|l|l||}
\hline Exp. & Solids & Conver. & Coagulum & $\mathrm{D}_{\mathrm{i}} / \mathrm{nm}$ & $\mathrm{D}_{\mathrm{v}} / \mathrm{nm}$ & $\mathrm{D}_{\mathrm{n}} / \mathrm{nm}$ & $\mathrm{PDI}$ & $\begin{array}{l}\mathrm{SCD} \\
\text { / } \mathrm{eq} / \mathrm{g}\end{array}$ \\
\hline \hline $012011 \mathrm{~S}$ & $14.62 \%$ & $61.57 \%$ & - & - & - & - & - & - \\
\hline 012011 & $25.15 \%$ & $96.82 \%$ & $0.65 \%$ & 224.4 & 220.1 & 204.1 & 1.09 & 81.0 \\
\hline $020311 \mathrm{~S}$ & $21.02 \%$ & $93.48 \%$ & - & - & - & - & - & - \\
\hline 020311 & $24.89 \%$ & $99.80 \%$ & $2.91 \%$ & 219.9 & 219.2 & 217.4 & 1.01 & 80.2 \\
\hline $020811 \mathrm{~S}$ & $15.76 \%$ & $62.82 \%$ & - & 197.5 & 183.1 & 153.8 & 1.28 & - \\
\hline 020811 & $24.50 \%$ & $92.18 \%$ & $1.78 \%$ & 239.0 & 237.6 & 226.1 & 1.06 & 64.5 \\
\hline $021611 \mathrm{~S}$ & $20.7 \%$ & $95.3 \%$ & - & - & - & - & - & - \\
\hline 021611 & $22.8 \%$ & $98.7 \%$ & $1.4 \%$ & 204.5 & 202.8 & 198.8 & 1.03 & 88.2 \\
\hline
\end{tabular}

Polymerizations were carried out by feeding the initiator solution with a syringe pump. The results are shown in Table 16. Slower styrene feeding resulted in an accumulation of monomer on top of the surface of the reactor contents and more coagulum was formed. However, the particle size and the surface charge density were similar. To prevent coagulum, a faster feed was 


\section{DE-EE0000278}

Dynalene Inc.

used for both comonomer solution and styrene. Compared with the highest surface charge density that was achieved in the $500 \mathrm{ml}$ scale, $110 \mu \mathrm{eq} / \mathrm{g}$, the surface charge density of latexes formed in a $2 \mathrm{~L}$ reactor is not good enough $(\sim 60-90 \mu \mathrm{eq} / \mathrm{g})$. So pre-emulsion feeding was used next to improve the surface charge density and a baffled reactor was used to improve the mixing.

Table 16: Results of the semi-batch copolymerization (Initiator Feeding)

\begin{tabular}{|l|l|l|l|l|l|l|l|l||}
\hline Exp. & Solids & Conver. & Coagulum & $\mathrm{D}_{\mathrm{i}} / \mathrm{nm}$ & $\mathrm{D}_{\mathrm{v}} / \mathrm{nm}$ & $\mathrm{D}_{\mathrm{n}} / \mathrm{nm}$ & $\mathrm{PDI}$ & $\begin{array}{l}\mathrm{SCD} \\
/ \mu \mathrm{eq} / \mathrm{g}\end{array}$ \\
\hline $030811 \mathrm{~s}$ & $18.4 \%$ & $83.8 \%$ & - & 217.2 & 202.1 & 155.0 & 1.40 & - \\
\hline 030811 & $23.4 \%$ & $99.9 \%$ & $0.9 \%$ & 232.4 & 228.9 & 210.7 & 1.10 & 88.1 \\
\hline $031011 \mathrm{~s}$ & $20.3 \%$ & $94.1 \%$ & - & 197.4 & 194.4 & 188.2 & 1.05 & - \\
\hline 031011 & $23.3 \%$ & $99.9 \%$ & $1.7 \%$ & 227.2 & 217.2 & 178.8 & 1.27 & 79.2 \\
\hline
\end{tabular}

The results for the pre-emulsion feed strategy are shown in Table 17. A uniform emulsion was formed in the baffled $2 \mathrm{~L}$ reactor at lower rpm. An addition funnel was used to feed the preemulsion into the reactor at first. However, the comonomer solution and styrene were not stable without adding surfactant and the emulsion was hard to form. Therefore, surfactants were added to stabilize the emulsion. However, the emulsion was only stable for several minutes. $\mathrm{N}_{2}$ bubbling was used in addition funnel to mix the pre-emulsion. The feeding rate is very hard to control by addition funnel. Instead, sonification was used to disperse the monomer and prepare a stable pre-emulsion. Only one surfactant was used with sonication to make the pre-emulsion stable for more than 1 hour. In this case the pre-emulsion can then be fed into the reactor and the feeding rate can be well controlled. The particle size and surface charge density did not significantly change by adding baffles to the reactor and feeding in a pre-emulsion feeding. Two filters were used to get rid of the coagulum. The first filter has $150 \mu \mathrm{m}$ pore size and the pore size of the second filter is $40 \mu \mathrm{m}$. Sometimes, there was a lot of coagulum that was captured by the second filter, and it was very hard to push the latex though the filter. When the particle size of the coagulum was measured, there was no difference between the final latex and the coagulum. So the coagulum formed by the second filter may be caused by the flocculation of the latex as it went though the second filter at high shear. So the $40 \mu \mathrm{m}$ filter was not used in the future experiments. The surface charge density was still not high enough compared to the smaller (500 $\mathrm{ml})$ reactor results.

Table 17: Results of the Semi-Batch Polymerization

\begin{tabular}{||l|l|l|l|l|l|l|l|l||}
\hline \hline Exp. & Solids & Conversion & Coagulum & $\mathrm{D}_{\mathrm{i}} / \mathrm{nm}$ & $\mathrm{D}_{\mathrm{v}} / \mathrm{nm}$ & $\mathrm{D}_{\mathrm{n}} / \mathrm{nm}$ & $\mathrm{PDI}$ & $\begin{array}{l}\mathrm{SCD} \\
\text { / } \mathrm{eq} / \mathrm{g}\end{array}$ \\
\hline \hline $032211 \mathrm{~S}$ & $21.1 \%$ & $92.0 \%$ & - & - & - & - & - & - \\
\hline 032211 & $21.5 \%$ & $99.9 \%$ & $0.1 \%$ & 230.7 & 227.4 & 210.5 & 1.09 & 82.1 \\
\hline $032211 \mathrm{BS}$ & $19.1 \%$ & $81.1 \%$ & - & - & - & - & - & - \\
\hline $032211 \mathrm{~B}$ & $22.3 \%$ & $99.9 \%$ & $0.8 \%$ & 253.7 & 253.1 & 235.2 & 1.08 & 83.5 \\
\hline $033111 \mathrm{~S}$ & $21.0 \%$ & $97.1 \%$ & - & - & - & - & - & - \\
\hline 033111 & $21.4 \%$ & $99.9 \%$ & $0.8 \%$ & 219.0 & 215.5 & 204.8 & 1.07 & 79.1 \\
\hline
\end{tabular}


DE-EE0000278

Dynalene Inc.

\begin{tabular}{|l|l|l|l|l|l|l|l|l|}
\hline 033111BS & $20.8 \%$ & $96.2 \%$ & - & - & - & - & - & - \\
\hline $033111 \mathrm{~B}$ & $21.5 \%$ & $99.9 \%$ & $0.2 \%$ & 230.3 & 227.6 & 216.0 & 1.07 & 80.4 \\
\hline
\end{tabular}

In most of the reactions, anionic comonomer A was used as the functional comonomer to supply the surface charge. However, the surface charge density was not high enough with relation to the cationic particles. This was probably caused by the limitation of the surface area on the anionic particle. Hairy structure of the functional comonomer on the surface would greatly improve the surface charge density and an anionic comonomer B was used in the feeding stage to achieve it. The reaction temperature was $60^{\circ} \mathrm{C}$, and the pitched-blade impellers (one-layer) were used with/without baffle during the polymerization reaction. 2 minutes of sonification was used to prepare the pre-emulsion feed with Triton 405 as surfactant. The pre-emulsion was fed in 2 hours, which was 30 minutes after initiator feeding was completed. The reaction was allowed to proceed for 8 hours at which point the heating was turned off with only stirring overnight. The reaction conditions can be seen in Table 18 .

The results of reactions are shown in Table 19. Initiator feeding was used to improve the consistency of radical generation rate. The baffled reactor showed improved mixing over the unbaffled reactor. Both reactions had high conversion. However, the surface charge density was not well improved. The difference of the surface charge density in those two reactions may be caused by the difference of the latex particle sizes. The surface charge density was limited by the surface area and hairy structure was not achieved.

Table 18: Reaction conditions used in the semi-batch copolymerization of styrene with comonomer B feeding (2 L)

\begin{tabular}{|c|c|c||}
\hline Exp. & $\mathbf{0 4 2 6}$ & $\mathbf{0 4 2 6 B}$ \\
\hline Impeller & $\begin{array}{c}\text { One-layer } \\
\text { Pitched-blade }\end{array}$ & $\begin{array}{c}\text { One-layer } \\
\text { Pitched-blade }\end{array}$ \\
\hline Baffle & No & Yes \\
\hline Stirring Speed & $250 \mathrm{rpm}$ & $200 \mathrm{rpm}$ \\
\hline Temperature & \multicolumn{2}{|c|}{$60^{\circ} \mathrm{C}$} \\
\hline Initiator Feeding & $5 \mathrm{~h}$ & $5 \mathrm{~h}$ \\
\hline \multicolumn{2}{|c|}{ Pre-emulsion Feeding } \\
\hline $\begin{array}{c}\text { Anionic } \\
\text { Comonomer }\end{array}$ & $\mathrm{B}$ & $\mathrm{B}$ \\
\hline Feeding Time & $2 \mathrm{~h}$ & $2 \mathrm{~h}$ \\
\hline Total Time & \multicolumn{2}{|c||}{} \\
\hline \hline
\end{tabular}


DE-EE0000278

Dynalene Inc.

Table 19: Results of the semi-batch copolymerization with anionic comonomer B feeding

\begin{tabular}{|c|c|c|c|c|c|c|c|c|c|}
\hline Exp. & Solids & $\begin{array}{c}\text { Percentage } \\
\text { Conv. }\end{array}$ & Coagulum & $\begin{array}{c}\text { Pre- } \\
\text { Feed } \\
\text { Particle } \\
\text { Size } \\
(\mathbf{n m})\end{array}$ & $\begin{array}{c}\text { Di } \\
(\mathbf{n m})\end{array}$ & $\begin{array}{c}\text { Dv } \\
(\mathbf{n m})\end{array}$ & $\begin{array}{c}\text { Dn } \\
(\mathbf{n m})\end{array}$ & $\begin{array}{c}\text { Poly } \\
\text { Dispersity } \\
\text { Index }\end{array}$ & $\begin{array}{c}\text { Surface } \\
\text { Charge } \\
\text { Density } \\
(\boldsymbol{\mu e q} / \mathbf{g})\end{array}$ \\
\hline $\mathbf{0 4 2 6}$ & $21.3 \%$ & $97.8 \%$ & $0.33 \%$ & 199.8 & 232.2 & 230.1 & 220.4 & 1.05 & 92.6 \\
\hline $\mathbf{0 4 2 6 B}$ & $21.1 \%$ & $96.2 \%$ & $0.05 \%$ & 208.3 & 241.2 & 239.4 & 225.0 & 1.08 & 76.4 \\
\hline
\end{tabular}

Then $10 \mathrm{~L}$ reactor was used for the next step scale up. The standard emulsion semi-batch copolymerization conditions used in $10 \mathrm{~L}$ are shown in Table 20. In $10 \mathrm{~L}$ reactor, the reaction temperature was $60{ }^{\circ} \mathrm{C}$, and the pitched-blade impellers (three-layer) were used at $150 \mathrm{rpm}$ with baffle for improving the mixing efficiency during the polymerization reaction. The reactor was under reflux and with an inert $\mathrm{N}_{2}$ blanket for the studies. The results are shown in Table 21 .

Table 20: Reaction conditions used in the semi-batch copolymerization of styrene with anionic comonomer $(10 \mathrm{~L})$

\begin{tabular}{|c|c|c|c|c|c|c|}
\hline Exp. & 0504 & 0512 & 0519 & 0616 & 0620 & 0707 \\
\hline Impeller & \multicolumn{6}{|c|}{ 3-layer-impeller (Baffle) } \\
\hline $\begin{array}{c}\text { Stirring } \\
\text { Speed }\end{array}$ & \multicolumn{6}{|c|}{$150 \mathrm{rpm}$} \\
\hline Temperature & $60^{\circ} \mathrm{C}$ & $60^{\circ} \mathrm{C}$ & $60^{\circ} \mathrm{C}$ & $70^{\circ} \mathrm{C}$ & $60^{\circ} \mathrm{C}$ & $60^{\circ} \mathrm{C}$ \\
\hline $\begin{array}{l}\text { Initiator } \\
\text { Feeding }\end{array}$ & $5 \mathrm{~h}$ & \multicolumn{5}{|c|}{ Half at beginning as a shot/Half fed in $4 \mathrm{~h}$} \\
\hline \multicolumn{7}{|c|}{ Pre-emulsion Feeding } \\
\hline $\begin{array}{c}\text { Anionic } \\
\text { Functional } \\
\text { Monomer }\end{array}$ & A & A & A & A & $\mathrm{C}$ & $\mathrm{A}+\mathrm{C}$ \\
\hline $\begin{array}{c}\text { Feeding } \\
\text { Time }\end{array}$ & $2 \mathrm{~h}$ & $2 \mathrm{~h}$ & $2 \mathrm{~h}$ & $2 \mathrm{~h}$ & $2 \mathrm{~h}$ & $1.5 \mathrm{~h}$ \\
\hline Time & \multicolumn{6}{|c|}{$7 \mathrm{~h}$} \\
\hline
\end{tabular}


DE-EE0000278

Dynalene Inc.

Table 21: Results of the semi-batch copolymerization of styrene with anionic functional

comonomers $(10 \mathrm{~L})$

\begin{tabular}{||c|c|c|c|c|c|c|c|c|c||}
\hline Exp. & Solids & $\begin{array}{c}\text { Percentage } \\
\text { Conv. }\end{array}$ & Coagulum & $\begin{array}{c}\text { Pre- } \\
\text { Feed } \\
\text { Particle } \\
\text { Size } \\
(\mathbf{n m})\end{array}$ & $\begin{array}{c}\text { Di } \\
(\mathbf{n m})\end{array}$ & $\begin{array}{c}\text { Dv } \\
(\mathbf{n m})\end{array}$ & $\begin{array}{c}\text { Dn } \\
(\mathbf{n m})\end{array}$ & $\begin{array}{c}\text { Poly } \\
\text { Dispersity } \\
\text { Index }\end{array}$ & $\begin{array}{c}\text { Surface } \\
\text { Charge } \\
\text { Density } \\
(\boldsymbol{\mu e q} / \mathbf{g})\end{array}$ \\
\hline \hline $\mathbf{0 5 0 4}$ & $14.3 \%$ & $56.9 \%$ & $<0.01 \%$ & 251.5 & 325.9 & 339.9 & 282.9 & 1.15 & 36.8 \\
\hline $\mathbf{0 5 1 2}$ & $21.3 \%$ & $96.6 \%$ & $<0.01 \%$ & 167.5 & 225.2 & 222.1 & 211.5 & 1.06 & 64.8 \\
\hline $\mathbf{0 5 1 9}$ & $21.4 \%$ & $97.3 \%$ & $<0.01 \%$ & 180.6 & 233.1 & 232.1 & 227.6 & 1.02 & 71.2 \\
\hline $\mathbf{0 6 1 6}$ & $21.6 \%$ & $98.7 \%$ & $0.10 \%$ & 191.5 & 199 & 183.3 & 149.1 & 1.33 & 57.6 \\
\hline $\mathbf{0 6 2 0}$ & $21.3 \%$ & $99.4 \%$ & $0.05 \%$ & 193.1 & 218.9 & 218.6 & 218.0 & 1.00 & 62.1 \\
\hline $\mathbf{0 7 0 7}$ & $22.1 \%$ & $97.5 \%$ & $<0.01 \%$ & 176.7 & 224.6 & 222.3 & 214.0 & 1.05 & 51.7 \\
\hline
\end{tabular}

The polymerization with initiator feeding by syringe pump was first used. The feeding time was 5 hours. However, the fractional conversion was low compared with reaction in $2 \mathrm{~L}$ scale (Figure 10). Particle size was larger and surface charge density was lower. This might be caused by insufficient generation of radicals. In the nucleation process, fewer radicals would result in fewer nuclei and would decrease the reaction rate and increase the particle size. Low surface charge density was probably caused by low conversion. So initiator was added one half at the beginning as one shot and then the other half was fed by syringe pump in 4 hours. With more radicals in the nucleation process, more nuclei were generated. The reaction rate was faster and fractional conversion was higher, which is compared with the $2 \mathrm{~L}$ scale. The pre-emulsion of functional monomer solution and styrene were fed one hour after the initiator feeding finished, when the conversion was higher. Pre-emulsion feeding time was 2 hours. When reaction temperature was switched from $60^{\circ} \mathrm{C}$ to $70^{\circ} \mathrm{C}$, the reaction rate was faster (shown in Figure 10) and particle size was smaller. However, the coagulum amount did not increase significantly. Another functional comonomer, anionic comonomer $\mathrm{C}$, was used to improve the surface charge density.

Comonomer $\mathrm{C}$ is a smaller molecular and occupies a smaller area. Because the surface area is limited, comonomer $\mathrm{C}$ may help improve the surface charge density. When scaling-up, the particle size, conversion and coagulum can be well controlled however, the surface charge density keeps decreasing with larger scale, which is shown in Table 22. It may caused by the different shear forces induced by the different impellers. Another problem is also about the mixing. In $10 \mathrm{~L}$ reactor, the shaft of impeller was stabilized by the bottom tip into the socket of shaft. However, sometimes the coagulum went into the space between the tip and socket and squeezed into harder and bigger coagulum, which influenced the mixing greatly. 
DE-EE0000278

Dynalene Inc.

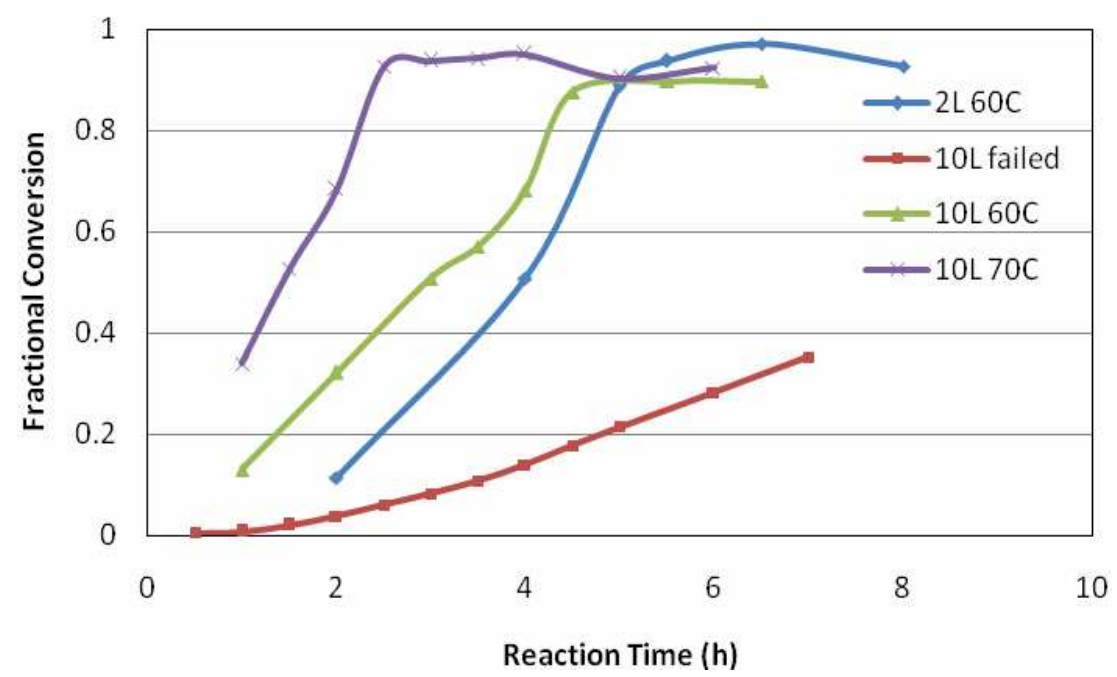

Figure 10: Fractional conversions of polymerization during the reaction.

Table 22: Results of the semi-batch copolymerization of styrene with anionic comonomer A at different scale

\begin{tabular}{|c|c|c|c|c|c|c|c|c|}
\hline Exp. & Solids & $\begin{array}{c}\text { Percentage } \\
\text { Conv. }\end{array}$ & Coagulum & $\begin{array}{c}\text { Di } \\
(\mathbf{n m})\end{array}$ & $\begin{array}{c}\text { Dv } \\
(\mathbf{n m})\end{array}$ & $\begin{array}{c}\text { Dn } \\
(\mathbf{n m})\end{array}$ & $\begin{array}{c}\text { Poly } \\
\text { Dispersity } \\
\text { Index }\end{array}$ & $\begin{array}{c}\text { Surface } \\
\text { Charge } \\
\text { Density } \\
(\boldsymbol{\mu e q} / \mathbf{g})\end{array}$ \\
\hline $\begin{array}{c}\mathbf{5 0 0} \\
\mathbf{m L}\end{array}$ & $19.95 \%$ & $91.5 \%$ & $0.8 \%$ & 243.6 & 238.4 & 210.9 & 1.15 & 112.8 \\
\hline $\begin{array}{c}\mathbf{2} \\
\mathbf{L i t e r}\end{array}$ & $22.3 \%$ & $99.9 \%$ & $0.8 \%$ & 253.7 & 253.1 & 235.2 & 1.08 & 83.5 \\
\hline $\begin{array}{c}\mathbf{1 0} \\
\text { Liter }\end{array}$ & $21.3 \%$ & $96.6 \%$ & $<0.01 \%$ & 225.2 & 222.1 & 211.5 & 1.06 & 64.8 \\
\hline
\end{tabular}

In the next set of experiments, more co-monomer $\mathrm{A}$ and the other functional monomer (Anionic co-monomer $\mathrm{C}$ ) were used in the feeding stage to improve the surface charge density in $10 \mathrm{~L}$ scale. The recipe of semi-batch with co-monomer $\mathrm{C}$ feeding is shown in Table 23. The reaction temperature was $60{ }^{\circ} \mathrm{C}$, and the pitched-blade impellers (three-layer) were used at $160 \mathrm{rpm}$ with baffle for improving the mixing efficiency during the polymerization reaction. The pre-emulsion was fed in 30 minutes, which was 45 minutes after initiator feeding finished. After 8 hours of reaction, the heating was turned off with only stirring overnight. 
DE-EE0000278

Dynalene Inc.

Table 23: Reaction Conditions Used in the Semi-batch Copolymerization of Styrene and Anionic co-monomer A/C

\begin{tabular}{|c|c|c||}
\hline Exp. & $\mathbf{0 8 0 2}$ & $\mathbf{0 7 2 1}$ \\
\hline Impeller & \multicolumn{2}{|c||}{ 3-layer-impeller (Baffle) } \\
\hline Stirring & $160 \mathrm{rpm}$ & $160 \mathrm{rpm}$ \\
\hline T & \multicolumn{2}{|c|}{$60^{\circ} \mathrm{C}$} \\
\hline KPS Feeding & $4 \mathrm{~h}$ & $4 \mathrm{~h}$ \\
\hline \multicolumn{3}{|c|}{ Pre-emulsion Feeding } \\
\hline \begin{tabular}{c|c|c||} 
Functional \\
Monomer
\end{tabular} & $\mathrm{A}$ & $\mathrm{C}$ \\
\hline $\begin{array}{c}\text { Feeding time } \\
\text { time }\end{array}$ & $30 \mathrm{~m}$ & $30 \mathrm{~m}$ \\
\hline \multicolumn{2}{|c|}{$6.5 \mathrm{~h}$} \\
\hline
\end{tabular}

The results of reactions are shown in Table 24. Initiator feeding was used to improve the consistency of radical generation rate. More Anionic co-monomer A in the feeding stage did not improve the surface charge density. However, the Anionic co-monomer $\mathrm{C}$ in the 30 minutes feeding stage significantly improved the surface charge density by almost $200 \%$. There is no such improvement, when co-monomer $\mathrm{C}$ was used as 2 hour feeding before. So the feeding rate of the co-monomer is critical for the hairy layer of functional monomer growth, which can help improve the surface charge density. When the feeding rate is fast, there is high concentration of co-monomer in the system, which can help the more co-monomer grow on the particle surface.

Table 24: Semi-batch Copolymerization with Anionic co-monomer A/C Feeding

\begin{tabular}{|c|c|c|c|c|c|c|c|c|}
\hline Exp. & Solids & Conver. & Coagulum & $\begin{array}{c}\text { Di } \\
\mathbf{n m}\end{array}$ & $\begin{array}{c}\text { Dv } \\
\mathbf{n m}\end{array}$ & $\begin{array}{c}\text { Dn } \\
\mathbf{n m}\end{array}$ & PDI & $\begin{array}{c}\text { SCD } \\
\boldsymbol{\mu} \text { eq/g }\end{array}$ \\
\hline \hline $\mathbf{0 8 0 2}-\mathrm{S}$ & $18.8 \%$ & $83.0 \%$ & - & 188.0 & 188.0 & 187.9 & 1.00 & - \\
\hline $\mathbf{0 8 0 2}$ & $21.9 \%$ & $98.2 \%$ & Negligible & 222.2 & 220.1 & 213.7 & 1.04 & 52.0 \\
\hline $\mathbf{0 7 2 1}-\mathrm{S}$ & $19.5 \%$ & $87.0 \%$ & - & 188.5 & 182.2 & 170.8 & 1.10 & - \\
\hline $\mathbf{0 7 2 1}$ & $20.6 \%$ & $93.1 \%$ & Negligible & 239.5 & 237.7 & 225.1 & 1.06 & 117.2 \\
\hline
\end{tabular}


DE-EE0000278

Dynalene Inc.

\subsubsection{Scale-up Nanoparticle Production to $100 \mathrm{~L}$}

Initial testing with the $100 \mathrm{~L}$ reactor testing began with dyed oil and water studies using the same methods as the $10 \mathrm{~L}$. It is necessary to decrease the stirring speed when scaling up because the tip speed on the larger impellers is much greater at the same RPMs. Too much shear creates unwanted results in the final latex, mostly coagulum and non-uniform particle distribution. The impellers were initially set up with geometric similarity to the final placement at the $10 \mathrm{~L}$ scale.

Testing was conducted at room temperature first to determine the minimum mixing speed to mix efficiently without shear. It was not possible to achieve complete mixing at a speed low enough to eliminate vortexing at the initial reaction volume. It was necessary to either add another impeller or reduce the volume in the reactor to increase mixing efficiency. It was determined to decrease the reaction volume to better fit the reactor with the current number of impellers. The impeller spacing was altered to work with the decreased reaction volume.

Testing was resumed at room temperature with the new impeller placement and decreased volume concentration. It was possible with the new set up to achieve complete mixing without the formation of a vortex. Photos of the dyed oil/ water mixing study can be seen below in Figures 11 (a-d).

Testing of the heating system began in conjunction with the mixing study. This allowed for testing the efficiency of the heating system while studying the effect of temperature on mixing efficiency. It was discovered at this time that the current heating system configuration was not able to heat the full volume of the $100 \mathrm{~L}$ reactor to the reaction temperature. A larger pump was installed in the heating system to increase the flow rate of the heating water through the reactor jacket. Testing was resumed and the reactor achieved the reaction temperature within two hours.

The impeller configuration and stirring speed were optimized at the $100 \mathrm{~L}$ scale with dyed oil and water at the initial reaction volume. Further testing was done to optimize the stirring conditions with the addition of the shot to the reactor. It was necessary to increase the stirring speed slightly once the shot addition began because the initial stirring speed was not sufficient for proper mixing of the increased reaction volume.

A stainless steel container was ordered and tested for shot addition. Systems were made and tested for gravity addition of both the initial monomer charge and the shot addition. The $100 \mathrm{~L}$ reactor was physically relocated to allow for more thorough ventilation to prevent any unsafe build-up of hazardous fumes. Safe distances were maintained from all electrical components and the $100 \mathrm{~L}$ reactor. All possible static hazards were properly grounded and tested to ensure safe operation throughout the duration of the reaction. 
DE-EE0000278

Dynalene Inc.

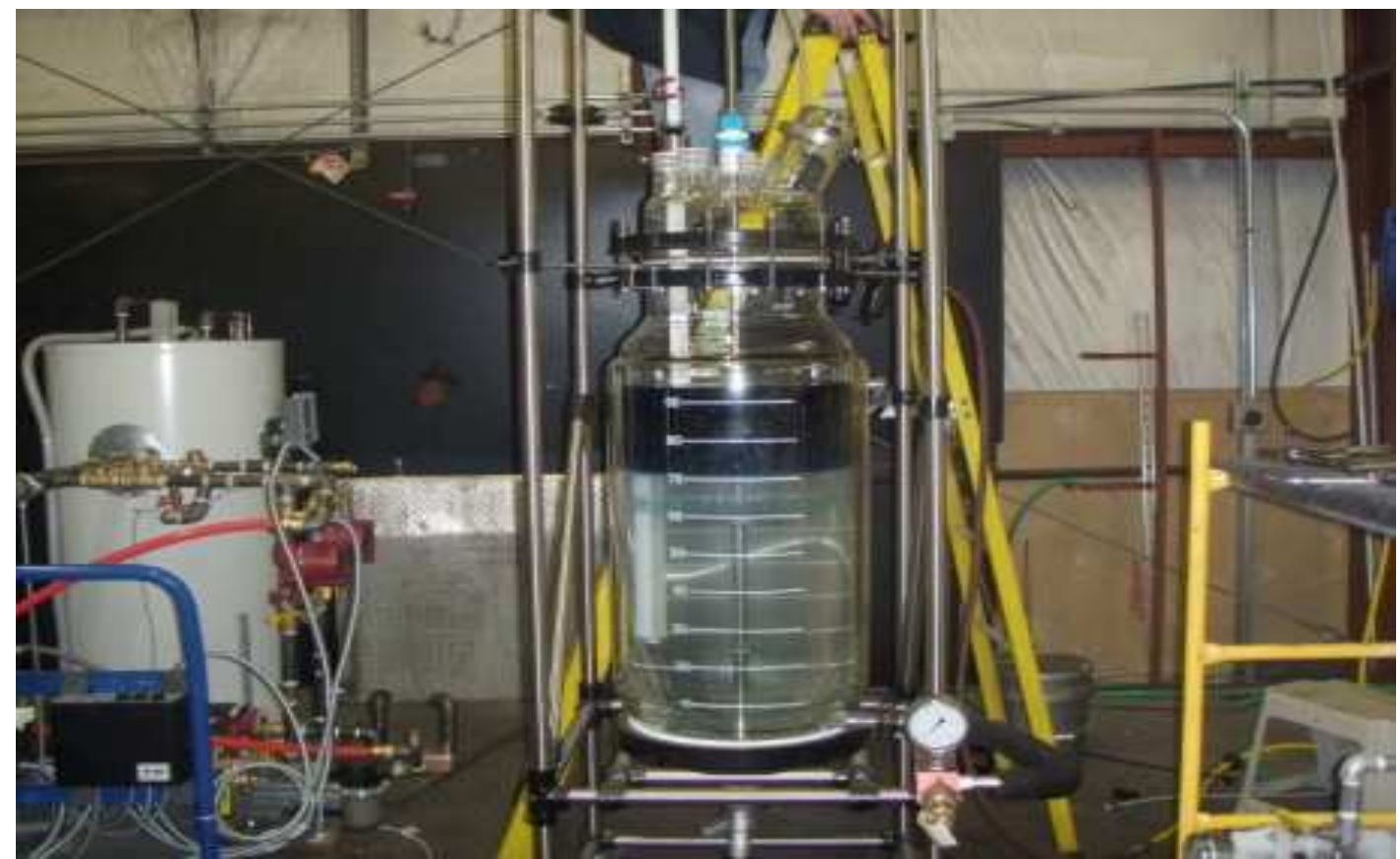

Figure 11a: Dyed oil/ water in $100 \mathrm{~L}$ reactor before mixing

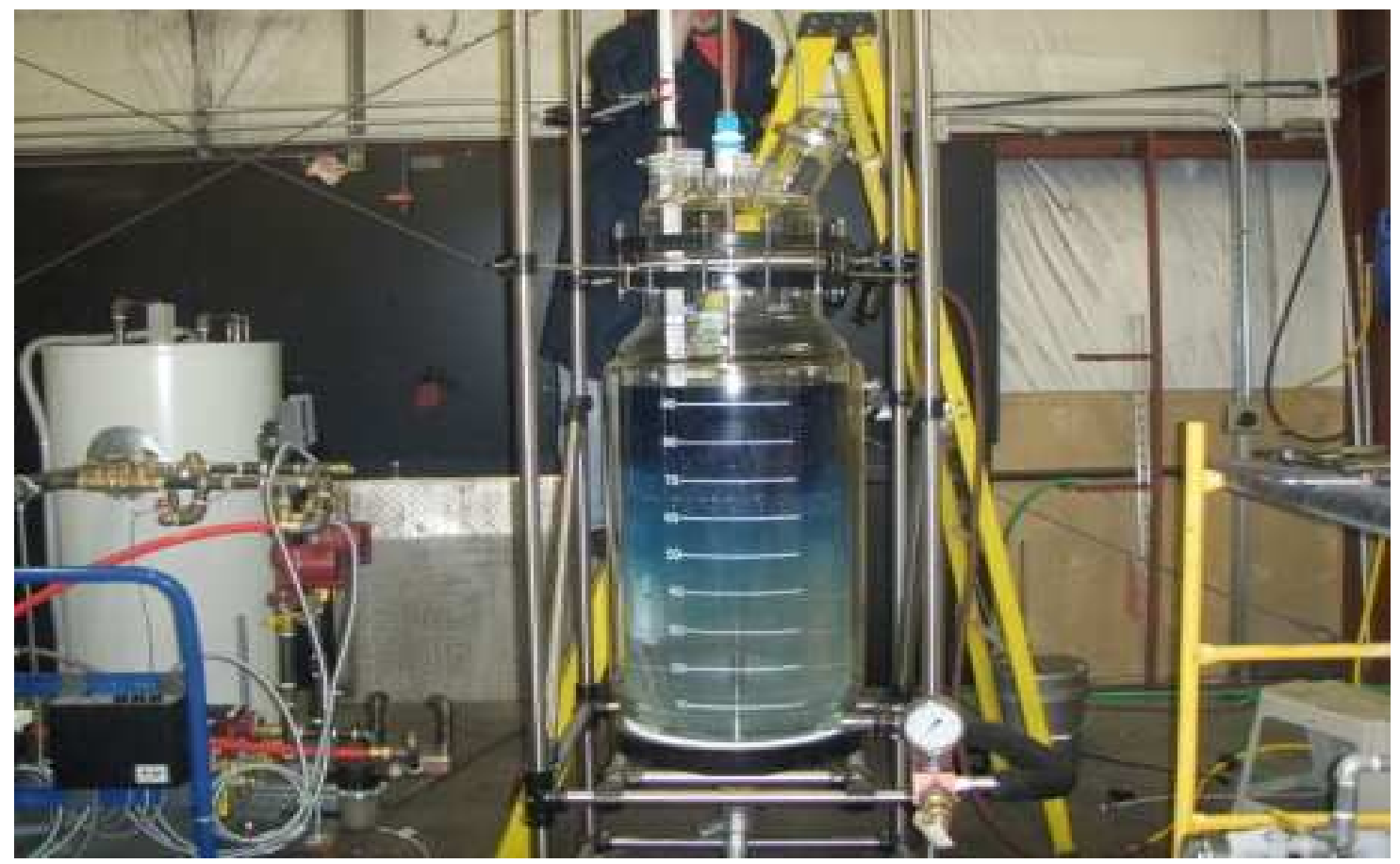

Figure 11b: 1 to 2 minutes mixing 
DE-EE0000278

Dynalene Inc.

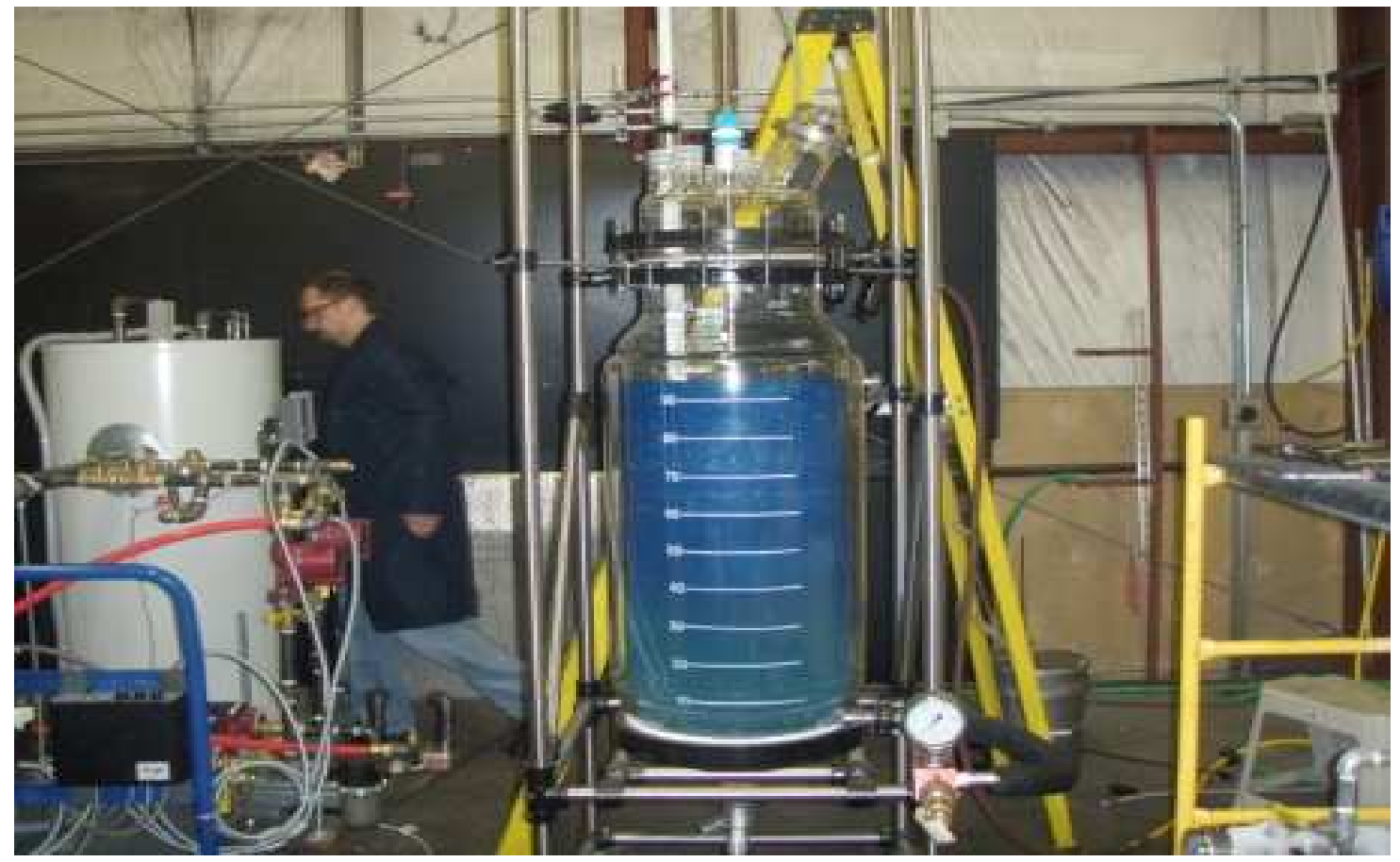

Figure 11c: 10 minutes mixing

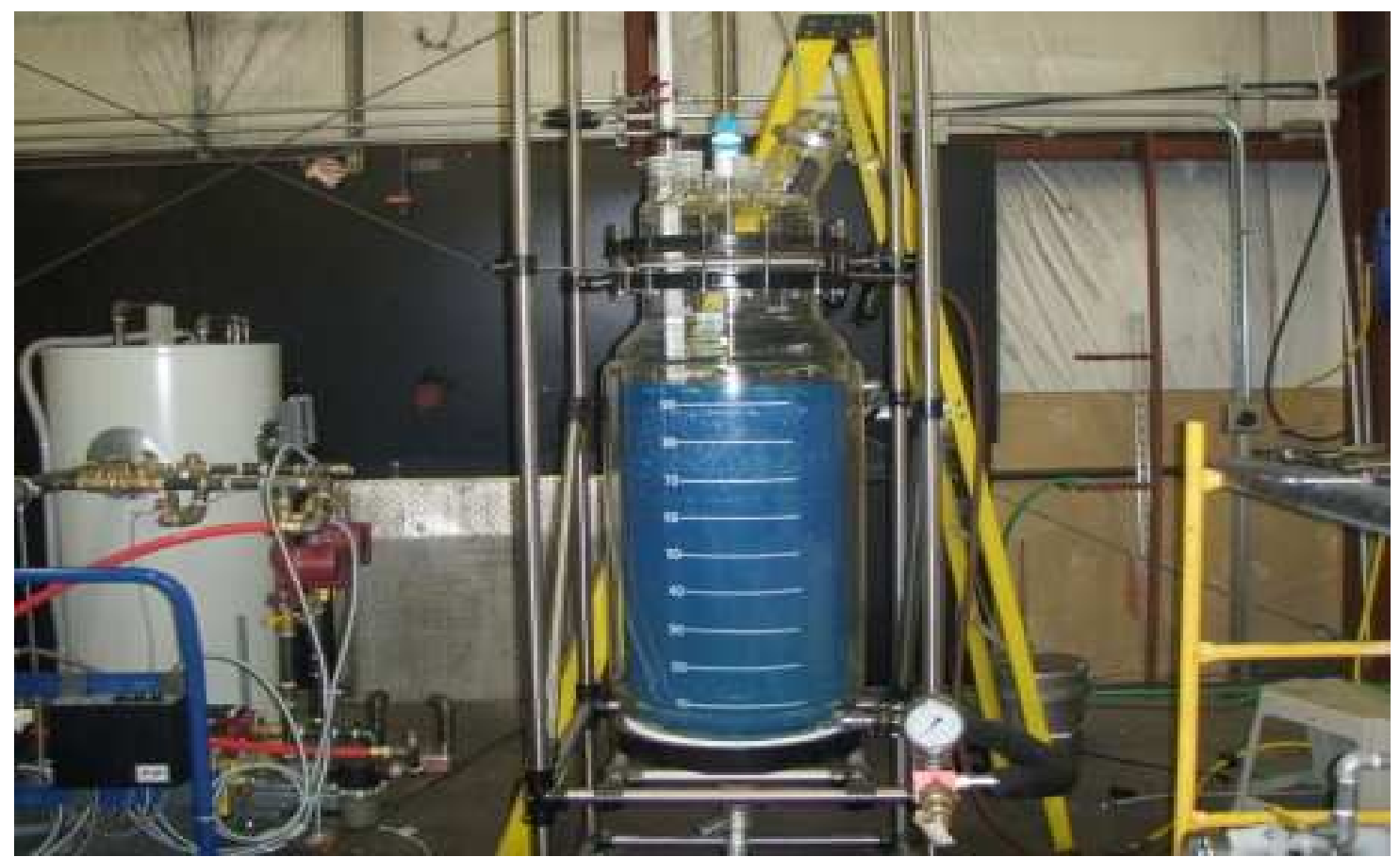

Figure 11d: 25-30 minutes mixing fully homogenized

When all safety precautions were installed and tested, a slightly smaller reaction was run in the $100 \mathrm{~L}$ reactor as a final test of all physical systems with the cationic reaction recipe. The final volume of the test reaction was roughly $60 \mathrm{~L}$. The impeller spacing for complete mixing was not 


\section{DE-EE0000278}

Dynalene Inc.

optimized for this volume therefore a good result was not anticipated. A large increase in the exotherm and reaction rate of the cationic synthesis occurred in moving from $2 \mathrm{~L}$ scale to $10 \mathrm{~L}$ scale. It was anticipated that a large increase in both would occur in moving from $10 \mathrm{~L}$ to $100 \mathrm{~L}$ scale. This was the main reason for running a test reaction with less volume. This increase did not occur. In fact, the reaction rate slowed considerably from the $10 \mathrm{~L}$ scale and only a slight exotherm was seen. The results of the test reaction can be seen in Table 25 .

Table 25: Results of the shot growth polymerization at $100 \mathrm{~L}$ scale

\begin{tabular}{|c|c||c|c|c|c||c|c|}
\hline Sample & $\begin{array}{c}\text { Time } \\
(\mathbf{h})\end{array}$ & $\begin{array}{c}\text { Di } \\
(\mathbf{n m})\end{array}$ & $\begin{array}{c}\mathbf{D v} \\
(\mathbf{n m})\end{array}$ & $\begin{array}{c}\text { Dn } \\
(\mathbf{n m})\end{array}$ & $\begin{array}{c}\text { Poly } \\
\text { Dispersity } \\
\text { Index }\end{array}$ & $\begin{array}{c}\text { Percent } \\
\text { Conversion }\end{array}$ & $\begin{array}{c}\text { Surface } \\
\text { Charge } \\
\text { Density } \\
(\boldsymbol{\mu e q} / \mathbf{g})\end{array}$ \\
\hline $\mathbf{1}$ & 0.5 & 113.1 & 101.4 & 98.9 & 1.14 & 12.7 & \\
\hline $\mathbf{2}$ & 1.0 & 148.8 & 133.7 & 130.2 & 1.14 & 29.0 & \\
\hline $\mathbf{3}$ & 1.5 & 178.1 & 168.1 & 159.4 & 1.12 & 50.0 & \\
\hline $\mathbf{4}$ & 2.0 & 199.1 & 189.3 & 179.8 & 1.11 & 72.4 & \\
\hline $\mathbf{5}$ & 2.5 & 224.6 & 206.5 & 201.3 & 1.12 & 99.0 & \\
\hline $\mathbf{6}$ & 3.0 & 226.9 & 218.1 & 203.8 & 1.11 & 100 & \\
\hline $\mathbf{7}$ & 3.5 & 234.5 & 225.7 & 219.3 & 1.07 & 100 & \\
\hline $\mathbf{8}$ & $\begin{array}{c}0.5 \text { after } \\
\text { shot }\end{array}$ & 349.9 & 389.8 & 378.6 & 1.08 & 97.5 & \\
\hline $\mathbf{9}$ & $\begin{array}{c}1.0 \text { after } \\
\text { shot }\end{array}$ & 313.5 & -- & -- & & 99.2 & 279 \\
\hline
\end{tabular}

All physical systems performed adequately during the lower volume test run. Coagulum was negligible, even less than on the smaller scale reactions. The surface charge density of the final latex was lower than the normal levels achieved at the $10 \mathrm{~L}$ scale. This could be due to the timing of the shot not being optimal for this first trial reaction.

A full volume $100 \mathrm{~L}$ reaction was run using the cationic recipe next. The results of this reaction can be seen in Table 26. The larger particle size by dynamic light scattering measurement was observed at the lower volumes as well. The surface charge density, although slightly lower than what was observed in the $10 \mathrm{~L}$ reactor, was still acceptable.

Table 26: Full size 100 L Cationic reaction

\begin{tabular}{|c|c|c|c|c|c||c|c|}
\hline Sample & $\begin{array}{c}\text { Time } \\
\text { hours }\end{array}$ & $\begin{array}{c}\text { Di } \\
\mathbf{n m}\end{array}$ & $\begin{array}{c}\text { Dv } \\
\mathbf{n m}\end{array}$ & $\begin{array}{c}\text { Dn } \\
\mathbf{n m}\end{array}$ & PDI & $\begin{array}{l}\text { Percent } \\
\text { Conversion }\end{array}$ & $\begin{array}{l}\text { Surface } \\
\text { Charge } \\
\text { Density } \\
(\boldsymbol{\mu e q} / \mathbf{g})\end{array}$ \\
\hline $\mathbf{1}$ & 0.5 & 127.1 & 114.2 & 111.3 & & 12.5 & \\
\hline $\mathbf{2}$ & 1.0 & 171.6 & 155.5 & 151.7 & & 25.2 & \\
\hline $\mathbf{3}$ & 1.5 & 180.5 & 170.5 & 165.9 & & 38.0 & \\
\hline
\end{tabular}


DE-EE0000278

Dynalene Inc.

\begin{tabular}{|c|c|c|c|c|c|c|c|}
\hline $\mathbf{4}$ & 2.0 & 202.5 & 192.4 & 182.4 & & 55.1 & \\
\hline $\mathbf{5}$ & 2.25 & 206.0 & 196.2 & 190.8 & & 64.0 & \\
\hline $\mathbf{8}$ & $\begin{array}{c}0.5 \text { after } \\
\text { shot }\end{array}$ & 368.3 & 393.6 & 384.0 & & 99.5 & \\
\hline $\mathbf{9}$ & $\begin{array}{c}1.0 \text { after } \\
\text { shot }\end{array}$ & 419.8 & 452.7 & 421.9 & & 99.7 & 350 \\
\hline
\end{tabular}

Then $100 \mathrm{~L}$ reactor was used for the final step scale up of the anionic particles. The standard emulsion semi-batch copolymerization recipes used in $100 \mathrm{~L}$ are shown in Table 27. In $100 \mathrm{~L}$ reactor, the reaction temperature was $60{ }^{\circ} \mathrm{C}$, and the pitched-blade impellers (three-layer) were used at $140 \mathrm{rpm}$ with baffle for improving the mixing efficiency during the polymerization reaction. The reactor was under reflux and with an inert $\mathrm{N}_{2}$ blanket for the studies. The pitchedblade (two-layer) was used at $160 \mathrm{rpm}$ for the pre-emulsion mixing. The results are shown in Table 28.

Table 27: Reaction Conditions Used in the Semi-batch Copolymerization of Styrene with Anionic co-monomer A/C (100 L)

\begin{tabular}{|c|c|c|c|}
\hline Exp. & 0818 & 0823 & 0825 \\
\hline Impeller & \multicolumn{3}{|c|}{ 3-layer-impeller (Baffle) } \\
\hline Stirring & \multicolumn{3}{|c|}{$140 \mathrm{rpm}$} \\
\hline $\mathbf{T}$ & $60^{\circ} \mathrm{C}$ & $60^{\circ} \mathrm{C}$ & $60^{\circ} \mathrm{C}$ \\
\hline $0.2 \mathrm{M}$ KPS & $5 \mathrm{~kg}$ & $5 \mathrm{~kg}$ & $5 \mathrm{~kg}$ \\
\hline $\begin{array}{c}\text { KPS } \\
\text { Feeding }\end{array}$ & $\begin{array}{l}1 / 2 \text { at beginning as a shot } \\
1 / 2 \text { fed in } 4 \mathrm{~h}\end{array}$ & \multicolumn{2}{|c|}{$\begin{array}{l}\text { 3/4 at beginning as a shot } \\
1 / 4 \text { fed in } 4 \mathrm{~h}\end{array}$} \\
\hline \multicolumn{4}{|c|}{ Pre-emulsion Feeding } \\
\hline $\begin{array}{l}\text { Functional } \\
\text { Monomer }\end{array}$ & A & $\mathrm{C}$ & $\mathrm{C}$ \\
\hline $\begin{array}{c}\text { Feeding } \\
\text { time }\end{array}$ & $30 \mathrm{~min}$ & $30 \mathrm{~min}$ & $30 \mathrm{~min}$ \\
\hline time & \multicolumn{3}{|c|}{$6.5 \mathrm{~h}$} \\
\hline
\end{tabular}


DE-EE0000278

Dynalene Inc.

Table 28: Results of the Semi-batch Copolymerization of Styrene with Anionic comonomer A/C (100 L)

\begin{tabular}{||c|c|c|c|c|c|c|c|c|}
\hline Exp. & Solids & Conver. & Coagulum & Di/nm & Dv/nm & Dn/nm & PDI & $\begin{array}{c}\text { SCD } \\
/ \mu \text { eq/g }\end{array}$ \\
\hline \hline $\mathbf{0 8 1 8 S}$ & $13.5 \%$ & $54.7 \%$ & - & 226.2 & 219.5 & 192.3 & 1.18 & - \\
\hline $\mathbf{0 8 1 8}$ & $19.2 \%$ & $84.8 \%$ & $0.01 \%$ & 280.0 & 282.5 & 273.3 & 1.02 & None \\
\hline $\mathbf{0 8 2 3 S}$ & $20.8 \%$ & $95.7 \%$ & - & 212.0 & 207.5 & 195.5 & 1.08 & - \\
\hline $\mathbf{0 8 2 3}$ & $20.4 \%$ & $93.1 \%$ & Negligible & 217.3 & 212.5 & 198.4 & 1.10 & 96.5 \\
\hline $\mathbf{0 8 2 5 S}$ & $20.6 \%$ & $93.0 \%$ & - & 206.6 & 203.6 & 196.6 & 1.05 & - \\
\hline $\mathbf{0 8 2 5}$ & $20.6 \%$ & $94.5 \%$ & Negligible & 225.9 & 221.8 & 206.5 & 1.09 & 79.3 \\
\hline
\end{tabular}

The same initiator solution feeding method, as used in $10 \mathrm{~L}$, was first used in reaction 0818 . The initiator solution was fed half at beginning and the other half fed by syringe pump in 4 hours. However, the fractional conversion and final conversion are lower in the $100 \mathrm{~L}$ reactor, which is compared with reaction in $2 \mathrm{~L}$ scale (shown in Figure 12). Particle size is also larger. Due to the low conversion, the latex cannot be cleaned by tangential flow filtration (TFF), and surface charge density cannot be measured. The similar problem happened when the scale was increased from $2 \mathrm{~L}$ to $10 \mathrm{~L}$. The conversion was lower and the particle size was larger in $10 \mathrm{~L}$ scale, when the initiator solution was fed by syringe pump in 5 hours. This might be caused by the insufficiency of radicals. In nucleation process, fewer radicals will result in fewer nuclei and will decrease the reaction rate and increase the particle size. So in reaction 0823, initiator solution was fed 3/4 at the beginning as one shot and then the other $1 / 4$ was fed by a syringe pump in 4 hours. With more radicals in the nucleation process, more nuclei were generated. With more initiator solution fed at beginning, the reaction rate was faster and the fractional conversion was higher, which is shown in Figure 13. The pre-emulsion of functional monomer $\mathrm{C}$ solution and styrene were fed one hour after the initiator feeding finished, when the conversion is more than $90 \%$. Pre-emulsion feeding time is 30 minutes. There is negligible coagulum and the surface charge density is $96.5 \mu \mathrm{eq} / \mathrm{g}$. In reaction 0825 , the pre-emulsion was fed just after initiator feeding, where the conversion is already more than $90 \%$. The final surface charge density decreased from $96.5 \mu \mathrm{eq} / \mathrm{g}$ to $79.3 \mu \mathrm{eq} / \mathrm{g}$. The long reaction time and higher conversion before the pre-emulsion feeding can improve the surface charge density of the final latex. When scale is from $10 \mathrm{~L}$ to $100 \mathrm{~L}$, the surface charge density is decreased from $117.2 \mu \mathrm{eq} / \mathrm{g}$ to $96.5 \mu \mathrm{eq} / \mathrm{g}$. This decreasing surface charge density problem also happened when scale is from $500 \mathrm{ml}$ to $2 \mathrm{~L}$ and from $2 \mathrm{~L}$ to $10 \mathrm{~L}$. The mixing efficiency, impeller shear force and reactor temperature profile changed during the scale up process. Those changes may be the reason for the decreasing surface charge density during the scale-up. Finally, the desired particle size and a reasonably high surface charge density latex was successfully produced in $100 \mathrm{~L}$ scale. 
DE-EE0000278

Dynalene Inc.

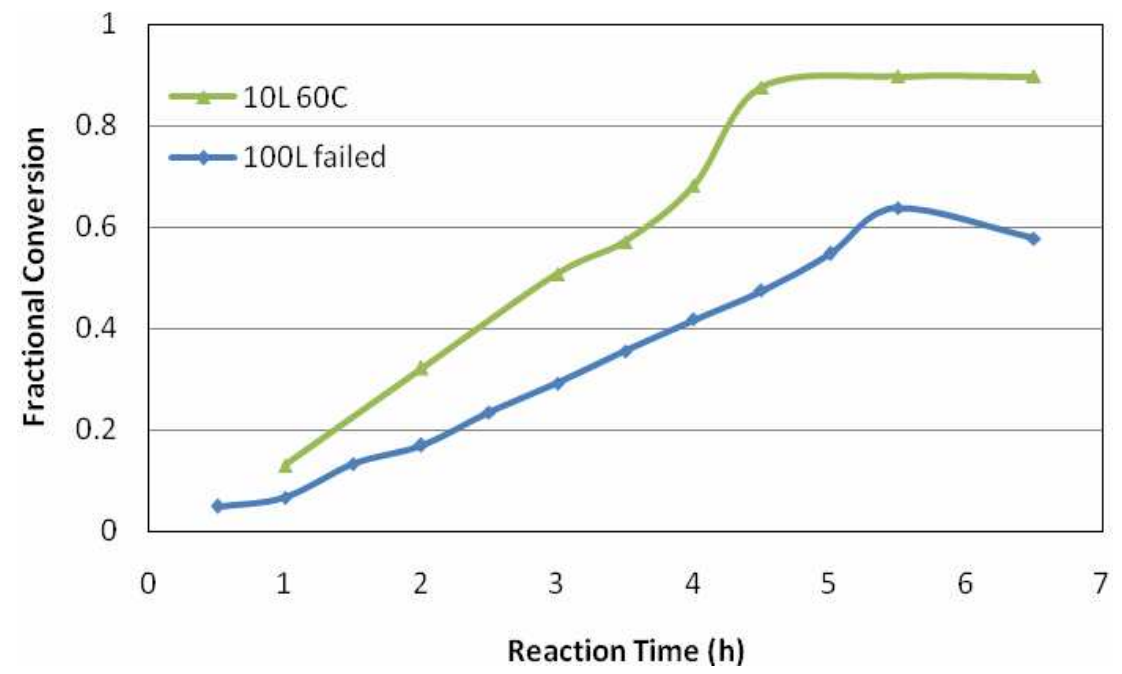

Figure 12: The fractional conversions of polymerization during the reaction with same condition in $10 \mathrm{~L}$ and $100 \mathrm{~L}$ reactors.

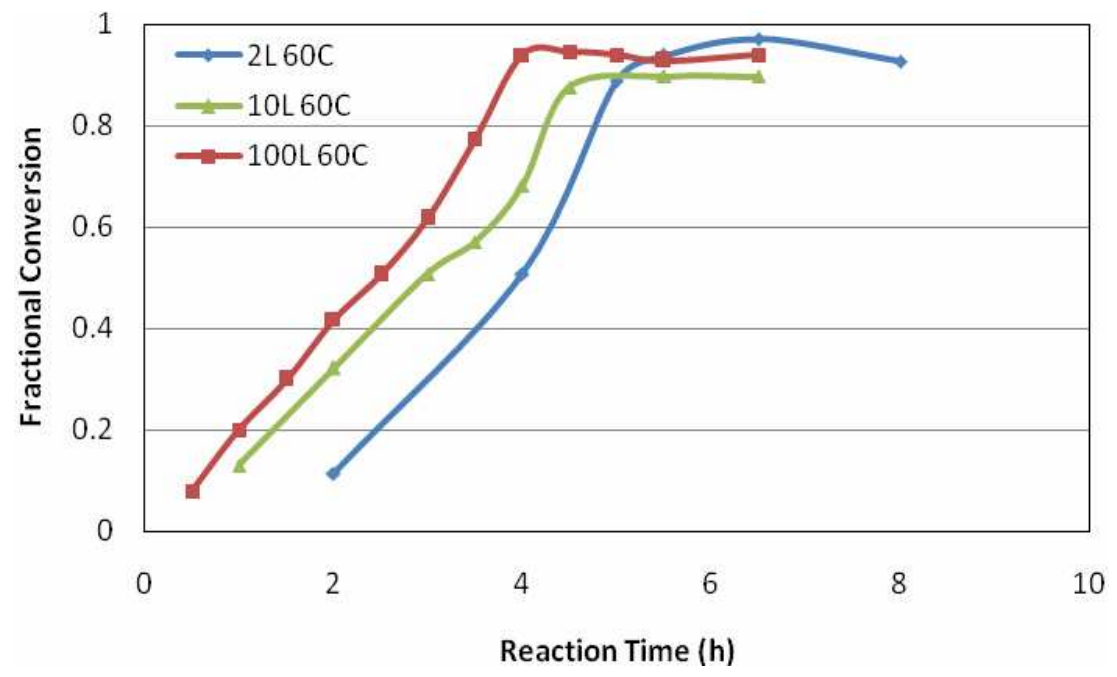

Figure 13: The fractional conversions of polymerization during the reaction with adjusted conditions in $2 \mathrm{~L}$ (initiator feeding in $5 \mathrm{~h}$ ), $10 \mathrm{~L}$ (half initiator fed at beginning and half feeding in $4 \mathrm{~h}$ ) and $100 \mathrm{~L}(3 / 4$ initiator fed at beginning and 1/4 feeding in $4 \mathrm{~h}$ ) reactors.

\subsubsection{Optimize Filtration Process}

More than fifteen batches of both anionic and cationic nanoparticles were produced at the $2 \mathrm{~L}$ and $10 \mathrm{~L}$ scale. To purify the nanoparticles, a filtration system was set up with two membranes instead of one to double the surface area for cleaning. A dilution of $2 \mathrm{~L}$ to approximately $16 \mathrm{~L}$ was necessary for purification. A system using a large reservoir and the vacuum caused by the 
DE-EE0000278

Dynalene Inc.

filtering was set up to constantly replenish the water lost during the process. This allowed for continuous filtering at a constant volume and decreased the time needed for cleaning from two or three days down to one day.

Following is a list of parameters that were optimized for this filtration process:

- Flow rate

- Pressure

- Concentration (solids percentage)

- Membrane pore size

- Membrane construction (PES or Ceramic)

- Additives

- Mixing in reservoir

More than thirty batches were purified using the optimized parameters. A representative curve of the permeate conductivity over the course of the purification is shown in Figure 14.

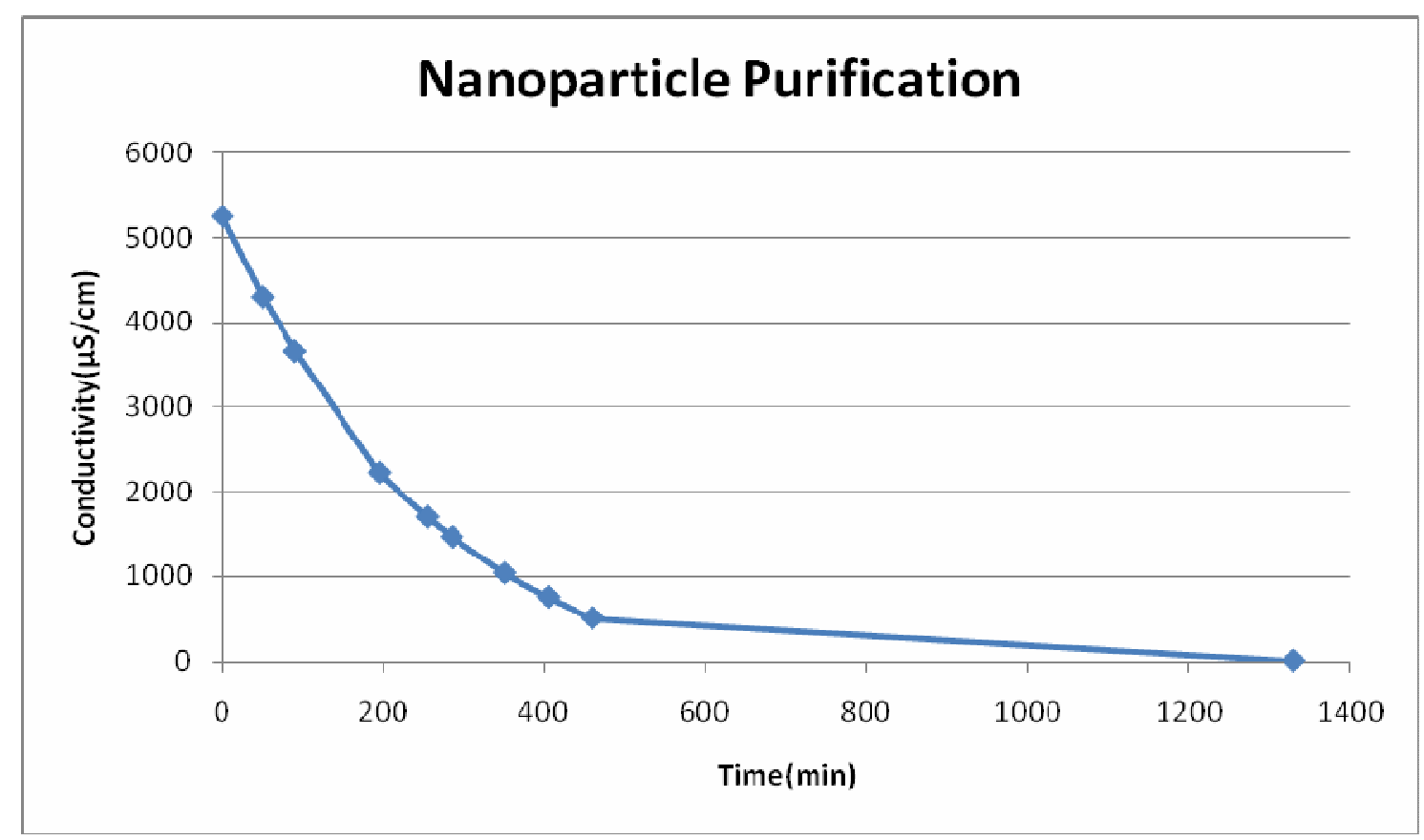

Figure 14: Nanoparticle purification curve

\section{Conclusions}


DE-EE0000278

Dynalene Inc.

This project allowed Dynalene researchers to synthesize and purify a key ingredient (nanoparticles) in the fuel cell coolant in large scale going from $2 \mathrm{~L}$ to $10 \mathrm{~L}$ and ultimately to 100 L. Each $100 \mathrm{~L}$ of nanoparticle translates to about 5,000 gallons of coolant. The following conclusions could be derived from this project:

- A semi-batch process is better suited than a batch process for the synthesis of the nanoparticles.

- The final particle size and charge density obtained (in the $100 \mathrm{~L}$ scale) are acceptable for the coolant manufacturing.

- Several parameters were identified and optimized to obtain the final particle size, charge density, low coagulum and a good kinetics of the reaction.

- For the filtration of the nanoparticles, several parameters were identified and optimized. The duration of filtration was reduced from several days to less than a day. 